\title{
Cognitive Theories of Early Gender Development
}

\author{
Carol Lynn Martin \\ Arizona State University
}

\author{
Diane N. Ruble and Joel Szkrybalo \\ New York University
}

\begin{abstract}
The contribution of cognitive perspectives (cognitive-developmental theory and gender schema theory) to a contemporary understanding of gender development is evaluated. Recent critiques of cognitive approaches are discussed and empirical evidence is presented to counter these critiques. Because of the centrality of early gender development to the cognitive perspective, the latest research is reviewed on how infants and toddlers discriminate the sexes and learn the attributes correlated with sex. The essence of cognitive approaches-emphasis on motivational consequences of gender concepts; the active, self-initiated view of development; and focus on developmental patterns-is highlighted and contrasted with social-cognitive views. The value of cognitive theories to the field is illustrated, and recommendations are made concerning how to construct comprehensive, integrative perspectives of gender development.
\end{abstract}

How individuals develop a "gendered" self and gender-typed differentiation has intrigued researchers of human behavior for as long as social development has been a field of empirical study. Initially, observations of clear gender typing in children as young as 5 years old led researchers to examine how socialization processes in the home might contribute to this early acquisition of gender-linked behavior (e.g., Sears, Maccoby, \& Levin, 1957). In 1966, several important theories of gender development, including Kohlberg's cognitive-developmental approach and Mischel's social learning approach, were outlined in Maccoby's book on the development of sex differences. In the mid-1970s, a groundbreaking book by Maccoby and Jacklin (1974) broadened the discussion about the etiology of sex differences and gender typing and questioned the significance of socialization processes, thereby invigorating the field and generating considerable controversy. In the 1980s, Huston $(1983,1985)$ called for researchers to develop a more integrative, comprehensive approach to the study of gender development. This integration was to include consideration of the many facets of gender that needed investigation, such as concepts,

Editor's Note. Janet Shibley Hyde served as the action editor for this article.-NE

Carol Lynn Martin, Department of Family and Human Development, Arizona State University; Diane N. Ruble and Joel Szkrybalo, Department of Psychology, New York University.

Preparation of the article was facilitated by a Russell Sage Grant for a Working Group on Social Identity and by National Institute of Mental Health Research Award MH37215 to Diane N. Ruble. We appreciate the helpful comments and suggestions made by Karen Adolph and Chuck Kalish. Thanks go to David Perry for his thoughtful advice about how to constructively compare theories and for his careful analysis of the commonalities between social-cognitive and cognitive views. Thanks are also due to Faith Greulich for providing support in preparation of this article.

Correspondence concerning this article should be addressed to Carol Lynn Martin, Department of Family and Human Development, Arizona State University, Tempe, Arizona 85287-2502. E-mail: cmartin@ asu.edu identity, preferences, and behavior, as well as a wide variety of factors that influence the development of these facets, including biology, cognitions, and social influences. This idea resonated with gender researchers and has been a driving force in the field ever since, leading to an expansion of theoretical approaches and the inclusion of multiple measures in empirical studies.

Recently, Bussey and Bandura (1999) presented a socialcognitive theory (SCT) of gender development and differentiation. This theory represents a particular view of how gender-related behavior is acquired and maintained, based on contemporary social learning theory (Bandura, 1986). Because the theory has now integrated cognitive constructs and makes reference to biological underpinnings and sociostructural factors, Bussey and Bandura described their theory as comprehensive and integrative, consistent with Huston's (1983) proposal, and implied that other theories are invalid and/or no longer necessary. In particular, they were highly critical of previous cognitive approaches to early gender development and proposed that children's cognitive structures, namely gender identity and stereotype knowledge, play a minor role relative to social forces. One goal of the present article is to rebut these claims.

A second goal is to present a contemporary account of the role of cognitive structures in early gender development. We begin with a brief history of the debate between cognitive and social learning theories of gender development. We then examine the contributions and limitations of Bussey and Bandura's (1999) recent account of gender development. Next, we review the current status of what have historically been the two major cognitive accounts of gender development: cognitive-developmental theory and gender schema theory. We then evaluate the empirical evidence relevant to the major controversies surrounding these views. Given the centrality of early gender development to the cognitive perspective, we then introduce the latest evidence on how infants and toddlers develop the abilities to discriminate the sexes and learn the attributes correlated with sex. Finally, we provide an overview of the essence of cognitive approaches and point to directions for future research. 


\section{A Theoretical Debate Begins}

In their two influential theoretical works about gender development, Walter Mischel, a social learning theorist, and Lawrence Kohlberg, a cognitive theorist, each suggested very different origins of gendered behavior and self-knowledge (Kohlberg, 1966; Mischel, 1966). Mischel (1966) emphasized the importance of environmental determinants of gender development (rewards and models) and suggested that behaviors precede cognitions (e.g., "I have been rewarded for doing boy things, I must be a boy"). Mischel's ideas were a direct outgrowth of learning-based approaches quite popular at the time. In contrast, Kohlberg (1966) emphasized the importance of children's growing understanding of gender categories and their permanent placement into one of them. He proposed that such cognitions precede behaviors (e.g., "I am a boy and thus like to do boy things"). Kohlberg's cognitivedevelopmental model represented a bold departure from the psychoanalytic and learning theories that held sway in the United States in the 1950s and 1960s. Furthermore, Kohlberg's heavy reliance on Piaget's work at a time when developmental psychologists were showing great interest in this work increased the likelihood that Kohlberg's theory would become a major influence on the direction of the field of gender development.

In the 1970s, several factors facilitated a shift in interest toward cognitive approaches. First, Maccoby and Jacklin's (1974) influential book raised questions about the underlying processes by which social forces shaped gender-typed behavior. Of particular importance was the issue of same-sex modeling as an explanation for sex differences. After reviewing more than 20 studies, they concluded that same-sex modeling is unlikely to account for sex differences in behavior, and a later review of over 80 studies corroborated this conclusion (Barkley, Ullman, Otto, \& Brecht, 1977). A second influence was more pervasive. The cognitive revolution in psychology in the late 1970s and the social psychological writings on cognitive influences on stereotyping (e.g., Ashmore \& Del Boca, 1979, 1981; A. G. Miller, 1982) facilitated the development of cognitive approaches to gender development (Constantinople, 1979). In the early 1980s, same-sex modeling regained some of its explanatory power on the basis of several studies showing that although children may not imitate one person, the likelihood of imitation increased with multiple same-sex models (Bussey \& Perry, 1982; Perry \& Bussey, 1979). The cognitive approach to gender development gained even more momentum with the advent of gender schema theories, including the versions that focused on individual differences (Bem, 1981; H. Marcus, Crane, Bernstein, \& Siladi, 1982) and those that focused on developmental issues (Liben \& Signorella, 1980; Martin \& Halverson, 1981). Although the versions of gender schema theory differed from one other and from Kohlberg's ideas, each of these cognitive approaches recognized the active and constructive processes involved in gender development.

The positions first proposed by Mischel (1966) and Kohlberg (1966), with their respective emphasis on environmental versus internal factors, underwent modifications over time. True to each theory's heritage, social learning theorists generally concentrated their efforts on the social sources of information about gender, whereas cognitive theorists focused their efforts on the nature of gender knowledge structures, how these structures are involved in processing information, and how they develop. Over time, how- ever, both approaches have moved toward the middle ground, with cognitive theorists showing more interest in the environmental factors that influence the construction and content of gender cognitions and learning theorists considering more seriously how cognitive and internal factors influence gender development. The changes in the social learning approach probably were the more dramatic, with a marked shift toward the inclusion of cognitive factors as important mediators and moderators of environmental forces. In short, the movement to be integrative and comprehensive has eliminated the strong form of the debate. It is now widely acknowledged that regardless of one's preferred theoretical orientation, cognitive, environmental, and biological factors are all important.

Unfortunately, Bussey and Bandura (1999) appeared to believe that by integrating other perspectives into their SCT, they were providing a comprehensive account of gender development. We disagree. Serious limitations and inconsistencies remain in this theory. Moreover, incorporating cognitive constructs into a social learning approach has not rendered obsolete alternative cognitive approaches. In the rest of the present article, we examine the concepts and the data to explain why.

\section{Overview and Critique of SCT}

In the decades following the publication of Mischel's (1966) chapter, social learning theory underwent several critical modifications (Bandura, 1977). As it evolved from its earliest manifestations, the major change in social learning theory has been toward a more cognitive orientation, as reflected by the inclusion of "cognitive" in its current title, social-cognitive theory (Bandura, 1986). In 1999, Bussey and Bandura introduced an SCT of gender development, which brought together these modifications and applied them to the topic of gendered conduct, much in the same way that previous articles have applied the theory to moral thought and action (Bandura, 1991b), self-regulation (Bandura, 1991a), and social referencing (Bandura, 1992).

\section{Strengths of SCT}

Among its most notable contributions, SCT introduced and elaborated on cognitive mechanisms and mediators of gendertyped behaviors, advancing learning theories beyond their earlier dependence on purely external factors and bringing them more in line with contemporary cognitive theories. Environmental events and contingencies are not viewed as the only source of gender role learning. With the adoption within SCT of Bandura's (1986) notion of triadic reciprocal causation and its application to gender development, environmental events, personal factors, and behavior patterns all interact and influence each other to produce gendertyped behaviors. In other words, internal variables-such as a child's biological preparedness to learn and engage in gendertyped behaviors, his or her emotional state, modeling experiences, self-standards, anticipated outcomes, and past success or failure in producing such gender-typed behaviors in other settings-are seen as playing important roles in the emergence and maintenance of gender-typed behaviors. The inclusion of these internal variables improved the capability of SCT to explain the consistencies and inconsistencies of children's gender-typed behaviors across time and settings over earlier versions of social learning theory. 
Over time, the view of the external environment has changed in learning theories, and these changes were reflected in the application of SCT to gender development. Whereas earlier learning theories presented the environment as a monolithic entity imposed on children, SCT stressed that children select and create their own environments as well. For instance, children may contribute to their gender role socialization through their selection of playmates and activities. A child who chooses to associate primarily with highly gender-typed, same-sex peers and engages in highly gender-typed activities is viewed as "constructing" an environment that perpetuates rigid adherence to gender norms. A child who associates with more egalitarian peers and engages in same-sex and other-sex activities constructs an environment that facilitates flexibility in gender norm adherence. The imposed environment nevertheless continues to exert an influence in SCT as, for example, when parents provide gender-typed toys and clothing for their toddlers or respond to gender-role-inconsistent behaviors with disapproval.

A cornerstone of the social learning perspective is learning through the modeling of others' behavior (Bandura, 1977, 1986). Bussey and Bandura (1999) followed in this tradition by stressing the importance of observational learning as a major vehicle for gender role learning. Modeling helped account for the rich and variegated repertoire of gender-typed behaviors that children are capable of learning without necessarily valuing and engaging in such behaviors. Earlier learning theories, which relied heavily on reward contingencies and punishments in explaining gender typing, could not account for children's capacity to learn complex gender-typed behaviors from adults and peers without a lengthy trial-and-error period. Modeling filled this gap by incorporating processes from cognitive approaches that mediated the acquisition and performance of gender-typed behaviors-processes such as attention to same-sex models, retention and mental rehearsal of observed gender-typed behaviors, internal standards of gender role conduct, and self-observation and self-reaction to gender-typed enactments (Bandura, 1986; Bussey \& Bandura, 1999). Children could thus absorb and integrate a wealth of gender role information from those around them without directly emitting gender-typed behaviors.

Bussey and Bandura's (1999) description of gender-related modeling was not merely confined to imitation of same-sex models. One significant aspect of their view of modeling was that it allowed children to exercise the capacity to produce new strings of behavior from their observations. Through internal (cognitive or cognitively influenced) attentional, retention, production, and motivational processes, children presumably learn the more abstract rules and styles of modeled behaviors and can then generate new symbolic variations. For instance, a boy may repeatedly observe older boys taking pleasure in a competitive, physical sport on the playground whereas the girls engage in more cooperative or sedentary activities. The boy may not simply imitate another boy who successfully participates in the sport; he may combine observations of several boys to come up with a unique approach to the game. He may also generalize the behavior by modeling the competitive and rough-and-tumble style that differentiates the boys from the girls on the playground, displaying this style in other activities besides the sport in question. Hence, as compared with imitation, modeling allowed for greater adaptation to new situations and greater complexity through the combination of modeled behaviors into new amalgams via the incorporation of cognitive processes (Bandura, 1986). Bussey and Bandura acknowledged that models do not always practice what they preach, such as when parents instruct their child to behave in a more gender-egalitarian manner but model highly gender-typed behaviors. Such discordance was not viewed as problematic in SCT. Rather, discordance within and between models could be used by children to discern whether and under what conditions modeled behaviors and attitudes should be adopted, again providing for greater adaptation and complexity than simple imitation.

Another contribution of SCT was its application of Bandura's (1986) notion of self-efficacy to gender role learning, highlighting it as the primary motivational component behind children's gender-typed behaviors. Self-efficacy refers to children's beliefs in their capabilities to produce desired outcomes through engaging in gender-typed (or gender-neutral) behaviors. According to Bussey and Bandura (1999), self-efficacy beliefs evolve out of experiences of graded mastery in the gender domain as well as observations of models successfully engaging in gender-linked behaviors. They influence other classes of motivators and thus supersede them, including goals, outcome expectations, causal attributions, and perceived opportunities. Self-efficacy beliefs are also seen as playing a crucial role developmentally. Bussey and Bandura described a period in children's early lives when their gender-typed behaviors and attitudes shift from being primarily subject to external regulation to being regulated internally. This transition is purported to occur after children have internalized cultural gender role proscriptions into a set of internal standards; they then observe and judge their own behaviors accordingly, administering self-praise or self-sanctions when behaviors meet or fall short of internal standards. Self-efficacy beliefs are important in determining whether children emit and persevere in gender-typed behaviors once they have established an internal basis for evaluating themselves. The establishment of internal standards of gender role conduct also helps to explain why some children persistently engage in gendertyped behaviors or voice highly gender-typed attitudes despite parental attempts to alter these behaviors and attitudes.

\section{Weaknesses of SCT}

A number of vital gaps nevertheless exist in Bussey and Bandura's (1999) application of SCT to gender development. To some extent, these gaps arise because some aspects of their theory may be characterized as "moving targets" in that their position has shifted back and forth across different published versions of the theory. This point is clearest in evaluating their stance on the role of gender identity in same-sex modeling.

In their 1999 article, Bussey and Bandura did not adequately explain how young children could selectively attend to same-sex models and associate gender-typed behaviors with each sex before they demonstrated the ability to correctly apply gender labels to themselves or others. They stated:

The ability to differentiate the two sexes and to link them to different activities and their associated social sanctions is all that is necessary for children to begin to learn gender role stereotypes. The children choose activities consistent with gender-linked stereotypes from having observed certain activities occur correlatively with the two sexes before they have a conception of gender. This level of understanding precedes gender self-identity, which already involves abstraction of a 
set of gender attributes integrated into a more general knowledge structure. (p. 695)

An unanswered question here is how children differentiate the sexes before they have at least a rudimentary conception of gender. What characteristics or cues are used as a basis for this differentiation? Why would children "choose activities consistent with gender-linked stereotypes" until they knew which sex they were? Curiously, in an earlier publication, Bussey and Bandura (1984) answered this question in ways that are very similar to cognitive theoretical approaches, namely with reference to personal identification with gender:

The ability to selectively adopt these behaviors displayed by same-sex models requires cognitive skills in categorization and judgment of similarity of self to others. (p. 1296)

Same-sex modeling seems to involve relying on classifying males and females into distinct groups, recognizing personal similarity to one group of models, and tagging that groups' behavior patterns in memory as the ones to be used as a guide to behavior. (p. 1297)

Similarly, in Bussey's early proposal (Bussey, 1983) about social-cognitive influences on gender development, she stated that "first, children must realize that there are two groups of people: males and females. Second, they recognize that they belong to one of the sexes. Third, they have the capacity to encode responses as being male- or female-appropriate" (p. 138). Thus, the recognition of the importance of cognitive mechanisms was made quite explicit in these articles.

By the early 1980s, then, social learning theory's account of modeling was remarkably similar to cognitive theories, an observation that did not go unnoticed by major figures in the field. According to Maccoby (1990), for example, this account

is very much the same as what cognitive developmental theorists have been saying all along: imitation depends on the formation of gender schemas, and on the consonance of incoming information with an already formed gender identity ... cognitive developmental theory and cognitive social learning theory no longer differ with respect to these elements in their accounts of sex typing. They both emphasize "self-socialization," to use the Maccoby and Jacklin (1974) term. (p. 11)

In their 1999 article, Bussey and Bandura reduced the similarity, in part, by abandoning the notion that recognizing personal similarity is a precursor to same-sex modeling. The logic underlying this stance is unclear. It would seem that children must be able to differentiate the sexes along some dimension(s) and know which of the two sexes is more "like them" if they are to attend to and imitate the behavior of same-sex models. This raises a related question about how children make judgments of similarity to same-sex models, including adults who bear much less of a physical resemblance to them than their age-mates. Bussey and Bandura were silent as to how children accomplish these complex, comparative tasks without understanding gender as a means for categorizing themselves and others.

Bussey and Bandura (1999) also argued that gender self-identity emerges out of cognitive processing of direct and vicarious experiences of gender typing in the environment. This argument stands in sharp distinction to cognitive-developmental theory, which views gender identity as a cognitive milestone that emerges over the normal course of biopsychosocial development and serves to channel gender-typed behaviors in children. Bussey and Bandura did not adequately explain how external factors such as modeling or direct tuition can lead to the development of an intrapsychic, cognitive construct like gender self-identity, a construct which they characterized in the first quote above as involving a level of abstraction and organization that is already fairly advanced.

Perhaps this apparent discrepancy is really more a shift in terminology than a shift in the nature of the theoretical process being proposed. ${ }^{1}$ It is difficult to believe that Bussey and Bandura truly meant to rule out an early role of basic gender identity, since throughout their 1999 article (and earlier writings, as quoted above) they refer to the importance of perceived similarity in same-sex modeling. Instead, their use of the term identity may mean something different from the way it is used by other cognitive theories, namely the simple recognition of being a boy or a girl. In some recent research, the term gender identity has been characterized as representing a more holistic and complex set of inferences involving self-perceptions of compatibility with one's gender group (Egan \& Perry, 2001). Bussey and Bandura may have had this more sophisticated notion of identity in mind. Thus, we assume that SCT is in agreement with the other cognitive theories that identity in the simple sense is a fundamental cognitive determinant of gender development. To minimize confusion, however, in the remainder of the article, we use the term self-labeling or the qualifier basic when referring to gender identity as the simple recognition of one's own sex.

Another weakness in Bussey and Bandura's (1999) model derives from their failure to impart a directedness to self-efficacy motives in gender development. Specifically, the cognitive mechanisms involved in children's acquisition of gender role knowledge and standards of conduct are not, in themselves, imbued with motivational significance. This raises fundamental questions about the motivational underpinnings of children's selective attention to same-sex models and their search for information about which gender domains are appropriate for them, both of which are needed to create self-evaluative standards and provide direction to selfefficacy. Self-efficacy accounts for gendered conduct after genderrelated information has already been acquired, but it does not account for the motivation to acquire such information in the first place.

Another significant gap in SCT is its lack of a clear description of one of the central processes of its theory, namely how external standards of gender role conduct become internalized into personal standards. Bussey and Bandura (1999) speculated that with the "development of self-reactive capabilities, the regulation of conduct gradually shifts from external direction and sanctions to self-sanctions governed by personal standards" (p. 697). How do these self-reactive capabilities arise? In an earlier article, Bussey and Bandura (1992) suggested that self-regulation develops "through the combined influences of modeling, tuition, evaluative feedback, and environmental structuring" (p. 1238), but they did not expound on the cognitive processes and structures that may be involved in this transition from external to internal regulation. It seems reasonable to assume that a precursor of internal regulation

${ }^{1}$ We are grateful to David Perry for suggesting this alternative interpretation. 
may be the development of a cognitive conception of self, one which can be observed, monitored, judged, praised or censured, selectively identified with models, and seen as efficacious. As alluded to above, Bussey and Bandura needed to be clearer in describing what aspects of the self emerge or play a crucial role at the juncture between external and internal regulation. Attending to and imitating same-sex models seems to imply a basic understanding of gender identity or self-labeling, but would this understanding be sufficient to precipitate a shift in cognitively mediated regulatory processes?

\section{Limited Empirical Bases of SCT}

Aside from the major conceptual difficulties of describing internal regulation without direct reference to basic gender identity or categorization abilities, Bussey and Bandura (1999) did not provide a thorough, convincing empirical base to support this or other components of their theory. To date, there are only two empirical studies directly applying SCT to early gender development (Bussey \& Bandura, 1984, 1992), although other studies have tested certain features of the theory with older children (see Bussey, 1983). The earlier of the two studies found that same-sex modeling occurred irrespective of children's level of gender constancy and that boys were more likely than girls to model cross-sex behaviors when social power was at stake. The main drawback of this study was that it did not explicitly examine the impact of earlier gender cognitions, such as gender labeling and preverbal knowledge of sex category distinctions, on sex-linked modeling. The counterintuitive finding of boys' cross-sex modeling also seems more consistent with cognitive theories than SCT because it suggests that children represent social power as a "masculine" endeavor and disregard the sex of the model when deciding whether to engage in such behavior. That is, boys' internal notions about what behaviors are appropriate for them override socialization pressures to model themselves after same-sex others.

The second study conducted by Bussey and Bandura (1992) sought to demonstrate that as children age, they begin to regulate their gender-typed behaviors on the basis of personal standards rather than social sanctions. Children were asked to indicate their anticipated evaluative reactions on a scale ranging from feeling "real great" to "real awful" with themselves or others for playing with particular gender-typed and neutral toys. Their results showed, as expected, that anticipated self-evaluative reactions differed as a function of the gender appropriateness of the toy and that these scores predicted gender-linked play with the toys for older children only. One difficulty of interpreting these findings is that the measure of evaluative self-reactions is problematic in a couple of ways. First, it might be quite difficult for 3-year-old children to report self-evaluative reactions because they were required to anticipate how they would respond if they were to play with a toy. Second, analyses of children's gender stereotypic knowledge about the toys indicated relatively low levels of knowledge and a correlation of knowledge with age. It is therefore possible that the reason for age differences in self-regulation was because the younger children did not know which toys were inappropriate for their sex and had no reason to report anticipating feeling "real awful," even if they were able to make such hypothetical anticipations. Thus, it is not clear that the failure of these scores to predict behavior for younger children is very meaningful.
In addition, the hypotheses involved a switch from social sanctions to self-regulation with age, but no analyses were conducted examining age differences in the impact of perceived social sanctions on gender-linked behavior. Bussey and Bandura (1992) argued that the data showed that children first learn to discriminate and evaluate gender-linked conduct and later learn to guide their own conduct by self-evaluative reactions. Unfortunately, no data supporting this assertion were provided. Self- and socialevaluative reactions were not directly compared in an analysis, and an examination of their Table 1, which presents these data, suggests no difference between self- and social-evaluative reactions for either age group. For example, younger girls' anticipatory self-evaluative rating for engaging in masculine-linked behavior was 3.2 (on a 5-point scale), and their four socialevaluative reactions to others engaging in cross-sex behavior were $3.0,3.0,3.2$, and 3.4 on the same scale. Thus, the data that are available suggest that self- and social-evaluative reactions did not differ. Additional, qualitative information about self-regulation is needed to gain a clearer picture of what personal gender standards supposedly consist of and how they differ from other gender cognitions, such as beliefs about the consequences of gender norm violations for the self and others.

Finally, Bussey and Bandura's (1992) study was cross-sectional in design. To lend weight to their model, they needed to show that children proceed through the developmental transition in which gender-linked behaviors are governed less by social sanctions and more by self-sanctions. In other words, a longitudinal design is needed to test this crucial component of SCT and to show that it occurs independent of children's labeling abilities, gender stereotype knowledge, and level of gender constancy.

Taken together, the findings from Bussey and Bandura's (1992) study actually provided little direct support for SCT's description of self-regulation and its role in gender development. Both of the above studies raised questions that would be fruitful to examine in follow-up studies, but to date they have not generated further research to strengthen and extend their conclusions. There has, of course, been considerable support for the basic principles underlying the application of SCT to gender development-for example, same-sex modeling, gender-related social reinforcement, and the significance of feelings of self-efficacy. Nevertheless, the unique effects of the cognitive components of SCT relative to other cognitive theories remain to be demonstrated.

\section{Discounting Cognition: Moving Against Integration}

On a broader front, Bussey and Bandura's (1999) contention that cognitive theories have been unsuccessful in describing gender development was inaccurate and surprisingly dismissive. Ultimately, their purpose appeared to have been to discredit the role of gender cognitions as organizers of other aspects of gender development. We believe this discounting of cognitive mechanisms and theories is misguided for several reasons. First, as discussed earlier, SCT needs cognition. This need for cognition was reified in the 1980s when cognitive features were integrated into the theory. Indeed, as Maccoby (1990) noted, SCT has incorporated ideas directly from cognitive theories over the course of its evolution from social learning theory. In 1986, Bandura argued that "children soon learn to use sex-typed information as a predictive guide for action" (p. 94). This statement is very similar to 
cognitive views on how children use gender knowledge as a "guide" for their behavior. In short, Bussey and Bandura simultaneously embraced and dismissed cognitive features of gender development. Not only did they fail to clarify how the cognitive elements of their theory differ from cognitive theories, but they also ignored the contributions of predecessors to their theory.

Second, a large part of Bussey and Bandura's (1999) critique of cognitive theories hinged on evidence that cognitions (e.g., stereotyped knowledge, gender labeling, and gender constancy) are not prerequisites for gender-typed behavior. Even if the data unequivocally supported this view (which they do not), it would not present a fatal blow to cognitive approaches. Kohlberg (1966) and others (e.g., Huston, 1983) fully acknowledged the influence of gender role socialization on children's behavior prior to the acquisition of gender cognitions. Martin and Halverson (1981), in their original proposal about gender schemas, also stated quite openly that "children could show some sex typing of behavior before the age at which schemas are present" (p. 1129). Cognitive perspectives have never denied that early gender-typed behavior may occur because of biological predispositions or because of processes emphasized by SCT, such as reinforcement. The issue is more complex than simply whether gender-related cognitions are essential prerequisites of gender-typed behavior. Instead, the issue is whether gender group identity or any other cognitive construction is particularly influential as a promoter or organizer of children's gender development.

Third, Bussey and Bandura (1999) did not consider the full range of evidence concerning the roles of cognitions on gender development. Gender-related cognitions have been demonstrated to play important roles in many aspects of gender development, but this evidence was largely ignored in their review of the research. For instance, the many experimental studies showing the powerful influence of novel gender cognitions on children's behavior, motivation, and memory were not considered in their review. Perhaps Bussey and Bandura's conclusions were heavily influenced by their own efforts to examine the role of cognitive constructs in gender development. For example, in one study (Bussey \& Bandura, 1992), they attempted to directly test predictions of SCT and cognitive-developmental theory side by side. Unfortunately, the data were not analyzed in a way that would facilitate the detection of gender constancy effects. ${ }^{2}$

Finally, it is possible that Bussey and Bandura's (1999) rejection of prior cognitive theories is partly due to their reliance on the earliest versions of the theories. For instance, when they discussed cognitive-developmental theory, they focused primarily on Kohlberg's (1966) original description of gender constancy as an organizer of gender acquisition, referring to recent literature only to note that there have been modifications in the assessment of gender constancy. Kohlberg's account was a groundbreaking departure from existing accounts of gender development at the time, including the predecessor to Bussey and Bandura's model, social learning theory. It was a kind of "first draft" of the theory, however, with numerous inconsistencies and occasional lapses in clarity that were easy to criticize; many prior to Bussey and Bandura did so (e.g., Huston, 1983). Bussey and Bandura also failed to appreciate that the cognitive-developmental account is considerably broader than the one they portray, emphasizing the active, cognitive construction of meaningful differences in oneself and the world.
Like social learning theory, cognitive-developmental theory was subsequently tinkered with and reformulated in important ways (e.g., Emmerich, 1982; Frey \& Ruble, 1992; Maccoby, 1990; Stangor \& Ruble, 1989; Wehren \& De Lisi, 1983). For example, the understanding of gender constancy is no longer viewed as an antecedent to all gender knowledge and gender differentiation. Instead, it is viewed as a point of increased susceptibility to gender-relevant information (Stangor \& Ruble, 1987) as well as a period of consolidation for conclusions about gender-appropriate activities (Ruble, 1994). Findings that children engage in gendertyped behavior prior to age 5-an observation even Kohlberg (1966) referred to- do not constitute a serious refutation of the basic tenets of contemporary cognitive-developmental theory, as Bussey and Bandura (1999) implied.

Similarly, some of Bussey and Bandura's (1999) criticisms of gender schema theory suggest that they were relying on the earliest versions of schema theory. In particular, they contended that gender schema theory does not specify the ways in which children abstract gender schemas. In the original publications on gender schema theory, Martin and Halverson (1981) and Bem (1981) described the origins of gender schemas in broad strokes, arguing that gender schemas form through innate tendencies of humans to classify and organize information, especially around salient dimensions. In the years since these early articles, however, gender schema theorists and other cognitive researchers have elaborated how gender schemas develop and how their content may be learned (Liben \& Bigler, in press). The development of gender schemas was extensively discussed in several review chapters (Martin, 1999; Martin \& Halverson, 1987) and in the Handbook of Child Psychology (Ruble \& Martin, 1998), as well as being the topic of a number of empirical studies (Bigler, Jones, \& Lobliner, 1997; Fagot \& Leinbach, 1989; Levy \& Carter, 1989; Martin \& Parker, 1995). Moreover, there is an extensive literature on the topic of schema development within social and developmental psychology. Although it is beyond the scope of this article to review all of the relevant literature, much research has been devoted to determining how children and adults represent and abstract information from what they see in the world around them and how this information is used to form categories (Medin, 1989) and concepts of social groups (Corneille \& Judd, 1999; Ford \& Stangor, 1992; Sherman \& Klein, 1994; E. R. Smith \& Zarate, 1992). Many of these ideas have been incorporated into writings on the development of gender schemas and stereotypes (see Martin, 1991). Bussey and Bandura's criticism on this point is surprising because some of the key processes in SCT require identical abstraction processes. For example, Bussey and Bandura suggested that for a child to move "from social sanctions to self sanctions" (p. 697), some form of mental representation is required and that "on the basis of direct and vicarious experiences, young

\footnotetext{
${ }^{2}$ Previous research has often found a sex difference, with boys showing greater effects of constancy on gender-linked behavior. Indeed, the data presented in Table 2 of Bussey and Bandura (1992) appear to indicate just such an effect. High-constant boys spent almost twice as much time engaged in masculine activities and almost half as much time engaged in cross-sex activities as did low-constant boys. The data were not analyzed separately by sex, and finding a sex effect in the analysis they used would have required a significant three-way interaction, an outcome that was unlikely given their small sample size (20 boys and 20 girls).
} 
children gain increasing knowledge about the likely outcomes of gender-linked conduct and regulate their actions accordingly" ( $p$. 697). They also referred to abstract modeling: "Once observers extract the rules and structure underlying the modeled activities, they can generate new patterns of behavior" (p. 686). These statements describe what is, in essence, a type of schema formation, making them quite compatible with schema theories. However, Bussey and Bandura provided few details about these abstraction and representational processes, and they did not describe how these processes differ from what schema theorists have been proposing.

In response to Bussey and Bandura's (1999) insufficient portrayal of cognitive theories and their selective critique of the evidence bolstering such theories, we now present a more contemporary description of the main features of and empirical support for cognitive-developmental and gender schema theories. Particular attention is devoted to the key cognitive structures for these theories: basic gender identity and gender stereotype knowledge.

\section{Cognitive-Developmental Theory}

\section{Major Features}

Cognitive-developmental theory focuses on a few central tenets. Perhaps the main feature that distinguishes it from other theories is its close link to basic cognitive development. What Kohlberg (1966) did that was so unique in developing his theory was to apply a Piagetian analysis of age-related changes in cognitive structures to the social domain (Emmerich, 1982). One critical component of the theory is gender constancy, which represents the developing understanding of the invariance of genderquite similar to the concrete-operational concept of conservation of physical properties. Constancy is usually represented by three stages (Slaby \& Frey, 1975): (a) children's growing realization that they are either a boy or a girl (called gender identity); (b) the recognition that this identity does not change over time (called gender stability); and (c) the recognition that this identity is not affected by changes in gender-typed appearances, activities, and traits (called gender consistency). Once children achieve this understanding about themselves, information about gender categories is believed to take on greater significance in how children respond to gender norms, develop relevant attitudes, and guide their behaviors. Cognitive-developmental theory also emphasizes that gender development involves an active construction of the meaning of gender categories, initiated internally by the child rather than externally by socialization agents. Finally, it argues that mastery or competence motivation is a driving force in gender development, as children seek to bring their perceptions and behaviors in line with their developing knowledge about gender categories.

Kohlberg (1966) was the first to posit that developmental changes in children's level of gender understanding are crucial for organizing other aspects of children's gendered behavior and thinking; however, his writing was not always entirely clear about the extent of gender knowledge required. In some places, Kohlberg seemed to suggest that a relatively basic level of knowledge was needed to organize gender development; in other places, he spoke about the critical importance of children acquiring more sophisticated levels of gender understanding before gender development would proceed full force. Not surprisingly, Kohlberg's ideas have been closely examined and reinterpreted to try to better understand what he meant about the level of gender understanding needed before children would be motivated to attend to same-sex others. Gender schema theorists have taken the stance that only basic levels of understanding are needed to provide such motivation (Fagot \& Leinbach, 1985; Martin \& Halverson, 1981). Contemporary cognitive-developmental theorists have agreed that basic gender identity has motivational significance but have also suggested that higher levels of gender understanding — namely, stability or consistency - may provide an additional or different kind of motivation for children to actively socialize themselves with regard to gender (Ruble, 1994). For example, basic gender identity may increase interest in and information seeking about gender, whereas more sophisticated levels of understanding may enhance children's desire to ensure that they are behaving in accordance with gender norms.

\section{Evaluation of Gender Constancy}

Given that sex differences in behavior occur well before the age that children develop a full understanding of gender constancy, the question for proponents of cognitive-developmental theory is whether children's cognitive constructions of gender influence their behaviors and whether gender constancy understanding plays any role in this process. The main hypothesis that has been tested is that higher levels of gender constancy are associated with an increased responsiveness to gender-related information and a more rigid application of gender norms. Numerous studies support the idea that gender constancy understanding influences gender-typed behaviors, but there are many mixed or null findings as well. Because the gender constancy literature has recently been reviewed elsewhere (Ruble \& Martin, 1998), we do not provide all of the details. Nevertheless, a few general points are worth making.

First, previous studies have found significant relationships between level of gender constancy understanding and numerous aspects of gender development: selective attention (e.g. LueckeAleksa, Anderson, Collins, \& Schmitt, 1995; Slaby \& Frey, 1975); same-sex modeling (e.g., Perloff, 1982; Ruble, Balaban, \& Cooper, 1981); same-sex activity, clothing, and peer preferences (e.g., Eaton \& Enns, 1986; Warin, 2000); gender stereotype knowledge (e.g., Coker, 1984; R. D. Taylor \& Carter, 1987); and affective indices of heightened responsiveness to gender (e.g., De Lisi \& Johns, 1984; Munroe, Shimmin, \& Munroe, 1984). In some cases, these relations hold for the highest stage of gender constancy, gender consistency; however, in more cases, they hold for the lower levels of gender stability or gender identity.

Second, reasons for some of the inconsistent findings have been identified. One reason is that examining relations in very young children may sometimes be misleading because many young children appear to show a phase of "pseudoconstancy" (Emmerich, Goldman, Kirsh, \& Sharabany, 1977; Szkrybalo \& Ruble, 1999; Wehren \& De Lisi, 1983). Many 3-4-year-olds get all of the answers to a forced-choice gender constancy measure correct, but they do not appear to really understand the constancy of being a boy or a girl. When asked to explain their answers, these pseudoconstant children do not provide constancy-relevant justifications for their responses (e.g., "It doesn't matter if he [stimulus picture of a boy in a dress] is wearing a dress; he'll always be a boy"). 
Instead, they tend to focus on irrelevant details (e.g., "He still has a boy's face") or show uncertainty ("I don't know"). It is not surprising, then, that cross-sectional and longitudinal studies often show a dip in scores on forced-choice constancy questions appearing at approximately age 4 followed by a recovery in scores 1 or 2 years later. This dip corresponds to a disjunction between forcedchoice responses and a particular kind of open-ended response, namely, social norm reasoning (e.g., "If Jack is wearing a dress, he must be a girl because boys don't wear dresses"). Perhaps the apparent high level of understanding by young children represents a kind of "centering" on the categorical distinction ("a boy is a boy"), rather than the integration of the social norm information with the category ("a boy is a boy even if he wears girls' clothes") needed for a true understanding of the permanence of gender. These findings suggest that in young children, scoring only the simple responses to the questions may overestimate their level of understanding, making it difficult to interpret the failure to find predicted relations with constancy in studies that only include preschool children (e.g., Bussey \& Bandura, 1984, 1992).

The notion of pseudoconstancy may be important for interpreting an influential article by Bem (1989). She suggested that once children understand the genital basis of sex categories, they show gender constancy, and that such an understanding can occur as young as 3-4 years of age. Two points about this study are noteworthy. First, it was not the only study to show a relatively earlier emergence of constancy understanding. Many studies have shown that a substantial proportion of children appear constant at this age, including the original study by Slaby and Frey (1975). It may be that a certain proportion (approximately 40\%) do show an early understanding, or it may be that at least some of these children are exhibiting pseudoconstancy. Second, just because children are aware of the connection between genitals and sex does not mean that they understand constancy. Some participants in our research have made it quite clear that they believe that genitalia can change with time (Frey \& Ruble, 1992). Moreover, young children may not confer special status to genitalia. A 3-year-old in one of our ongoing studies said he was a girl when attention was drawn to his ponytail but said he was a boy when attention was drawn to his penis.

Another reason for some of the inconsistent findings relating constancy to gender typing is that relations may occur only under certain conditions. In particular, relations between constancy attainment and same-sex imitation or gender-consistent toy preferences appear to be especially likely under conditions of conflictthat is, when the relevant behavior involves accepting an unattractive toy associated with the same sex and avoiding an attractive toy associated with the other sex (Frey \& Ruble, 1992). When no conflict is involved (e.g., the toys are gender neutral or when same- and other-sex toys are equally attractive), level of constancy understanding either does not exert an influence on children's same-sex modeling or toy choice (e.g. Bussey \& Bandura, 1984, 1992; Perloff, 1982) or a relation is shown with lower levels of constancy understanding, such as gender identity or stability (e.g., Bussey \& Bandura, 1984; Martin \& Little, 1990; Weinraub et al., 1984). How may these patterns of findings be interpreted? It requires little motivation for children to select a gender-consistent over a gender-inconsistent activity when the two are equally attractive. To "play it safe," they are likely to avoid the inconsistent activity even if they have only a minimal understand- ing of gender (e.g., "I am a girl and this is a boys' toy"). A dilemma is presented, however, when such a choice involves sacrificing the opportunity to play with a more attractive and interesting toy. In such a case, additional motivation to abide by gender norms is needed. The data suggest that children with higher levels of gender constancy understanding possess this additional motivational impetus to avoid attractive "other-sex" activities (Frey \& Ruble, 1992; Newman, Cooper, \& Ruble, 1995; Stangor \& Ruble, 1989; Zucker et al., 1999). An accurate assessment of the role of the motivational effects of gender constancy understanding (as well as other constructs thought to affect the motivation to adhere to gender norms, such as self-regulation) may require incorporating conflict conditions as part of the study.

A final general point about relations with constancy, alluded to above, is that Kohlberg (1966) may have erred in emphasizing the final stage of gender constancy - gender consistency - as the most important level of understanding for motivating gender role adherence in children (Maccoby, 1990; Martin \& Little, 1990; Ruble $\&$ Martin, 1998). When the literature on relations between level of gender constancy and responsiveness to gender-related information is reviewed, gender consistency does not emerge as the crucial component (Ruble \& Martin, 1998). Instead, significant relations often involve lower levels of understanding, such as gender stability and even gender identity. Does this observation invalidate cognitive-developmental theory? As Maccoby (1990) notes, Kohlberg may have been right about the motivational importance of a firm gender identity for promoting gender differentiation, even if this identity emerges earlier than Kohlberg thought-that is, prior to full gender constancy. The crucial cognitive achievement in Kohlberg's view is children's recognition of the categorical significance of gender, which in turn motivates them to comply with gender norms at a particular point in development. This process is cognitive-developmental whether it occurs at 3-5 years or 5-7 years of age or whether it occurs in relation to understanding the stability rather than the consistency of gender identity. The notion that gender conceptions influence behavior is not refuted simply because Kohlberg thought gender consistency signified the critical developmental achievement in this process. He may have had the right idea, but the wrong signifier. Studies looking at the effects of gender labeling and/or identity per se (see Basic Gender Understanding (Identity or Labeling) as an Organizer of Gender Development) provide further support for this idea.

\section{Conclusion}

In short, the literature to date provides considerable support for Kohlberg's (1966) original contention that children's growing understanding of their sex category membership has motivational significance. Exactly when and how this understanding affects children's gender-related choices and behaviors remains unclear, however. Research and theorizing since 1966 have suggested that the kind of effect may change with increased understanding of constancy such that lower levels may orient children to the importance of gender (e.g., information seeking, choice of friends), whereas higher levels may heighten children's behavioral responsiveness to gender norms, particularly under conditions of conflict. This developmental hypothesis remains to be tested, and a longitudinal examination would be particularly useful. 
Moreover, the exact nature of the motivation linking level of constancy to preferences and behaviors remains the subject of debate. Two possible consequences of achieving a complete understanding of constancy have been discussed in the literature (Ruble \& Martin, 1998). One interpretation is that the understanding that gender is invariant across time and situation prompts children to master gender norms, so that a peak in children's rigid adherence should occur at the highest level of constancy understanding (e.g., Frey \& Ruble, 1992). An alternative interpretation is that until children achieve constancy, they may be concerned that violating gender norms threatens their basic gender identity (D. E. Marcus \& Overton, 1978). In this case, a full understanding of gender constancy should be associated with greater flexibility in the application of gender norms rather than rigidity (Huston, 1983). It may be that both processes operate to some extent: Higher levels of constancy understanding are increasingly associated with a rigid adherence to norms, but then once children are truly certain their sex will not be affected by their behavior, they begin to behave more flexibly. These critical issues about the timing of rigidity in relation to constancy and the underlying motivations (e.g., fear of changing sex or mastery) are only beginning to be tested empirically (L. Taylor, Ruble, Sumner, \& Szkrybalo, 2002; Warin, 2000).

\section{Gender Schema Theory}

\section{Major Features}

Like cognitive-developmental theory, gender schema theory has at its core a few central tenets. First, cognitions about gender are central to gender development. Specifically, children form gender schemas - that is, organized networks of mental associations representing information about themselves and the sexesthat influence information processing and behavior. Gender schemas are viewed as dynamic knowledge representations that show age-related development as a function of interactions between the individual and his or her environment as well as changes in response to situational variations.

Second, like cognitive-developmental theory, gender schema theory assumes that the child plays a very active role in his or her own gender development. Children's active role is obvious in their constructive information processing as well as in their motivation to adhere to gender-related behaviors. Schemas are not seen as passive copies of the environment; instead, they are viewed as active constructions, prone to errors and distortions. Schemas direct children in an active manner, in that children are motivated to seek information about gender as soon as they can identify themselves as boys or girls. More specifically, once they recognize their membership in a gender category, children seek details and scripts for same-sex activities and are more attentive to differences between boys and girls.

Third, schema theories emphasize the active guidance of schemas through two major mediating processes linking gender schemas to behaviors. One is through schema-directed memory. Young children attend to and remember more script-like information about same-sex, self-relevant activities and thus know more about how to perform behaviors consistent with gender norms (Ruble \& Stangor, 1986). A second mediating process is more similar to cognitive-developmental theory: Children are motivated to be- have in accordance with gender norms as a means of defining themselves and attaining cognitive consistency. Other factors, such as the salience of schemas, situational demands, children's developmental level, individual differences in the chronic accessibility of schemas, and the perceived expectations of others also influence whether children will match their behavior to their gender knowledge structures (Martin, 1993; Martin, Fabes, Evans, \& Wyman, 1999). Furthermore, some children may initially develop idiosyncratic schemas or ones that match the other sex more than their own sex, and these could direct children's behavior, although the pattern would not be easily discernible. For instance, girls who are "tomboys" may have a different type of schema than a more typical girl, and the tomboy schema could allow her more flexibility in her behavior and thinking. Similarly, children's interests in attractive activities or in future high-status jobs may modify their schemas; when children have strong personal interest in an activity typically associated with the other sex, their schemas may become more flexible (Liben \& Bigler, in press). Thus, the influence of gender schemas on behavior and thinking is dependent on many factors within the child and the environment.

\section{Developing Gender Schemas}

In cognitive theories, the development and application of knowledge structures related to gender are emphasized as playing important roles in gender development. Although cognitivedevelopmental and gender schema theories have historically differed in their focus on one form of knowledge versus another, they share interest in how various types of gender schemas form and function. Not surprisingly, cognitive theorists have been central in outlining possible mechanisms and processes involved in abstracting gender-related information from a highly gendered environment and in using this information to form gender schemas. The focus in these accounts is on the active and constructive processes involved in gender development, ones in which children go beyond the information given to develop and elaborate their concepts of the sexes. Their gendered concepts are less-thanveridical representations, which vary from time to time and place to place. From research conducted on gender, categorization processes, and social cognition, evidence has accumulated in support of the notions about schema development put forth in the cognitive approaches. Below we outline some of the basic ideas involved in schema development.

Cognitive theorists assume several underlying principles are involved in the development of gender schemas. The first principle is that humans have a tendency to use functionally significant and salient categories, like gender, to classify and organize information from their environments (Bem, 1981; Martin \& Halverson, 1981). Imagine what children face in learning about a social category: Information is often complex and ambiguous, and covariations among groups and attributes may be weak. Nonetheless, children discern markers of social categories and notice if and when one group tends to engage more frequently in particular behaviors or occupations, and so on, as compared with the other group. These tendencies to notice even relatively weak covariations, or statistical regularities, have been confirmed in young infants' perception of tones and phonemes and in adults' perception of visual scenes (e.g., Fiser \& Aslin, 2001; Saffran, Aslin, \& Newport, 1996; Saffran, Johnson, Aslin, \& Newport, 1999). Certain factors in- 
crease the likelihood that children attend to social groups and then learn about them. An important factor (but probably not a necessary one) in schema development is physical appearance, specifically, physical differences between members of distinct groups; for instance, men tend to be taller than women, and girls tend to have longer hair than boys. Empirical studies have confirmed that categories are formed around physical appearance differences for salient groups (Bigler et al., 1997). In the Bigler et al. (1997) study, even when children were placed in arbitrary groups (either in the blue or yellow group), they attended to the categories and used them to make judgments of others when the categories were both physically salient (by having blue or yellow T-shirts to distinguish group members) and when these groups were functional (e.g., teachers lining children up by group).

The second principle concerning the development of knowledge structures is that there is an underlying coherence (or a perception of coherence) to many categories, such as natural kind categories and some social categories (Gelman, 1989; Gelman \& Markman, 1987; Keil, 1991; Medin, 1989; Rothbart \& Taylor, 1990; M. G. Taylor, 1996). The driving force behind the coherence of categories is the assumption that individuals make that members of a category share some underlying similarity or "essence." This belief and the associated idea of groupness (i.e., entitativity) can be promoted through physical differences among groups (Dasgupta, Banaji, \& Abelson, 1999) or through labels given to different group members (even arbitrarily; Gelman, 1989; Gelman \& Markman, 1987).

The third principle is that categorization promotes inductive reasoning, which allows individuals to go beyond the information that is immediately available to them. Inductive reasoning, in turn, promotes the growth of knowledge structures. Thus, even when knowledge of a person is very limited, it is possible for individuals to use the available information to tap into a much wider knowledge structure, thereby allowing for inferences to be drawn despite individuals' lack of relevant direct experience. In some cases, these inferences become part of the knowledge structure. There is strong empirical evidence that children use categories to make inductive inferences about members of natural kind categories (Gelman, 1989; Gelman \& Markman, 1987; Keil, 1991) and that they use gender knowledge as a basis for generalizing to other group members (Berndt \& Heller, 1986; Cann \& Palmer, 1986; Cowan \& Hoffman, 1986; Haugh, Hoffman, \& Cowan, 1980; Lobel, Bar-David, Gruber, Lau, \& Bar-Tal, 2000; Lobel \& Menashri, 1993; Martin, 1989; Martin, Eisenbud, \& Rose, 1995; Martin, Wood, \& Little, 1990; Zucker, Wilson-Smith, Kurita, \& Stern, 1995). Children also use gender groups as a way to demarcate boundaries when they learn new information about individual group members. For example, a child who is told about a girl who has "estro in her blood" is likely to infer that estro is a quality of other girls (even if they do not look like girls) and not of other boys (Gelman, Collman, \& Maccoby, 1986). Similarly, preschool children make assumptions about shared interests among group members belonging to the same group and do not generalize this to non-group members, even when they have no relevant information on which to base such assumptions (Martin et al., 1995).

The fourth principle is that there are cognitive consequences of categorization that further promote the development of knowledge structures. Categorization encourages individuals to exaggerate between-group differences and enhance within-group similarities, as social identity theorists such as Tajfel and colleagues (e.g., Tajfel, 1981; Tajfel \& Turner, 1986; Turner, Hogg, Oakes, Reicher, \& Weatherell, 1987) have so clearly demonstrated. Physical differences or labels for groups (e.g., woman, man) signal individuals to notice other group differences, to exaggerate group differences, or even to create illusory group differences. These ideas can be difficult to test with preexisting social groups. Consequently, much of the research has been done with arbitrary groups, such as the minimal group paradigm, or with unfamiliar groups, such as outer-space creatures.

For example, in a classic minimal group study, adults were shown a graduated series of sticks and were given two different labels for the groups. Adults tended to remember the sticks within the same-labeled group as being more similar in size to one another, and they remembered the sticks given different labels as being more dissimilar to one another than they were in reality (Tajfel \& Wilkes, 1963). Similar inaccuracies were shown in a study of learning about unfamiliar social categories. Adults were exposed to information about two groups of outer-space creatures in five sessions over 2 weeks. The results showed that judgments about similarities and differences between the creatures were influenced by group membership. Even after the first session, physical differences between groups were exaggerated relative to similarities between groups, and this pattern held over the multiple presentations about the groups (Martin \& Bullock, 1986).

Children may even use their knowledge of gender in humans to make assumptions about sex differences in other unfamiliar species of creatures from "outer space." In one study (Martin \& Rose, 1991), children were shown a set of creatures and were asked over two trials to select one of them who was a "boy" and one who was a "girl." In one variation on this procedure, the two types of creatures differed in head shape. This variation sought to test whether children would assume that male and female space creatures look different even when the basis of the difference was not one found in humans. Any consistency children attributed between head shape and gender group labels would have been due to their developing and applying abstract ideas about the sexes being physically different. Using several variations of head shape, children showed strong consistency in applying different gender labels to creatures that looked different. In a follow-up study of over 100 young children (Martin \& Rose, 2001), four variations of appearance were compared and children continued to demonstrate the application of these "theories of categorization."

The kinds of active information processing we have been describing are essentially adaptive learning strategies that enable children and adults to notice, remember, and sometimes even create group-attribute correlations and to form coherent categories from them. Categorization provides organization, which facilitates information processing, which in turn, can become the building block for the development of new knowledge bases. Key processes, such as children's ability to use induction to make a wide variety of inferences about groups, provide children with a powerful set of tools for noticing differences between groups and for developing and elaborating their schemas about groups. These processes allow children to be "prepared" for learning from the environment and give them the ability to go beyond what they see to develop abstract constructions about the sexes. Similar development and abstraction processes probably operate as part of self-concept development when children learn to place themselves 
in relation to gender groups - gender identity - as discussed in the next section. A complete picture of gender development requires knowledge of the processes and outcomes associated with the development of simple gender categories as well as with more elaborate gender-related cognitive structures. Knowing more about these processes will facilitate understanding of how and when gender concepts are applied in children's behavior and thinking.

\section{Conclusion}

Building on cognitive-developmental principles, gender schema theory spurred researchers to investigate many areas typically not considered important to gender development. In particular, the theory addressed the broad topics of how children abstract information from their social environments and apply that information to social groups and themselves. Furthermore, gender schema theory emphasized the importance of understanding how children use knowledge structures to organize memory and described how these knowledge structures influence children's attention, motivation, impressions of others, and behavior. Gender schema theory also has its weaknesses. Gender schemas are elusive - these constructs are difficult to define and measure. And, true to the heritage of this theory, there has been more interest and emphasis on internal processes than on biological or social inputs to gender development. Less interest has been shown in the variability of gender development than in its consistency. Another criticism of the theory is that gender cognitions have been more directly applicable in predicting thinking, memory, attention, and inferences about others and have been somewhat less so in predicting behavior (see the next section). Nevertheless, gender schema theory has been a heuristic theory that has suggested new directions of research and has greatly expanded the topics studied by gender researchers.

\section{Controversial Issues Concerning Cognitive Theories}

Are gender cognitions as central to gender development as cognitive theorists propose? Although this is a complex issue, the debate has, unfortunately, settled into one simple set of ideas. Specifically, the reasoning is that if gender cognitions are influential in directing behavior, then links between these cognitions and behavior should be apparent, and conversely, if these links are not found, then gender cognitions must not be influential in gender development. At the outset, it is important to state that this thinking represents an oversimplification of the problem and of cognitive views. Both gender schema theory and cognitivedevelopmental theory consider that children may show evidence of gender-typed behavior before they have developed gender-related cognitions. Nonetheless, there is an expectation in cognitive theories that cognition is important and that it serves as an organizer and motivator for both behavior and thinking. Thus, from a cognitive perspective, the issue is better conceptualized as trying to understand when and how cognitions function in gender development. Below we summarize the empirical evidence concerning the organizational role of two types of gender cognitions- basic gender identity and gender stereotypes - on children's behavior and thinking.
Basic Gender Understanding (Identity or Labeling) as an Organizer of Gender Development

Central to cognitive views is the idea that basic gender identity guides behavior. Before reviewing the evidence on this issue, it is important to clarify several points. First, cognitive theorists consider that children's recognition of their own sex and their membership in a gender group is informative and central to their motivation to learn about gender. Unfortunately, few studies (Fagot \& Leinbach, 1985) have specifically targeted children's knowledge of their own gender group (here we call this basic gender identity). Instead, most have used children's ability to verbally label the sexes (here we call this gender group labeling) as a proxy for this knowledge. One important empirical question not yet conclusively answered is whether children's basic gender identity develops at the same time as labeling abilities. Thus, gender group labeling studies, although providing insights into a critical aspect of gender development, may not truly tap into the type of knowledge that cognitive theorists consider central and fundamental to children's self identity.

In addition, gathering relevant data to test the organizational function of gender cognitions is difficult. To date, two approaches have been available to test the effects of children's capacity to label and identify with a gender category. The first and easiest is to examine concurrent correlations between level of gender group label/identity and extent of gender-typed preferences and behaviors. The problem with this kind of analysis is that it must be restricted to toddlers and young children because, as Fagot (1985) suggested, labels for the sexes may be so overlearned by ages 3-4 that there is insufficient variability for correlational analyses.

The few studies conducted with young children confirm that gender group labeling and/or identity relates to behavior. For instance, Fagot (1985) found that young children who were able to label the sexes or who could label and identify their own sex spent more time with same-sex peers than those who could not label the sexes. In addition, boys who had developed gender cognitions (labels or identity) showed less play with other-sex toys. Girls with an understanding of identity showed an increased tendency to play with same-sex toys over other-sex toys, although the pattern was not significant.

The relation between gender group labeling and behavior was examined in another study of young children (21-40 months old; Fagot, Leinbach, \& Hagan, 1986). As the authors stated,

\footnotetext{
Of three types of behavior in which early sex typing has been found consistently, two are related to children's ability to apply the labels "boy" and "girl" accurately: preference for same-sex playmates and aggressive acts. Children who succeeded at the gender labeling task spent more time playing with members of their own sex, and girls who succeeded at the task showed almost no aggression in the classroom. (p. 442)
}

The third sex-typed behavior, preference for sex-typed toys, was not significantly correlated with labeling acquisition. Children showed a general preference for same-sex toys, and these preferences were unrelated to gender group labeling abilities.

Other studies also provide support for the influence of gender labels on behavior. In a study of children from 14 to 35 months of age, assessments were made of gender labeling abilities and observed play with a set of gender-typed and neutral toys over a 6-month period (O'Brien \& Huston, 1985). Although the data were 
collected over time, the data concerning links between cognition and behavior were not analyzed longitudinally. About half these young children were able to reliably differentiate males and females. It is important to note that the ability to correctly apply gender labels related to masculine toy preferences for boys, but for girls, the correlation between feminine toy play and gender labeling could not be separated from changes associated with age. Finally, Weinraub et al. (1984) found a significant relation between children's ability to verbally label themselves by sex and sex-typed toy preferences (but no relation with gender labeling of the sexes).

Failures to find significant patterns may be due to the lack of clarity in defining children's level of gender understanding or to the lack of response variability in the measures. In one of Bussey and Bandura's studies (Bussey \& Bandura, 1992), children with the lowest levels of gender knowledge (labeling/identity) showed preferences for same-sex toys over other-sex toys, but there were no children who were nonlabelers to act as a comparison group.

In older children, finding any evidence of gender labeling/ identity effects is more difficult, partly because many children have already acquired a basic understanding of gender. Nonetheless, Martin and Little (1990) examined several aspects of young children's gender understanding, gender stereotypes, and genderrelated preferences. Even in the youngest group (35-45 months old), the majority of children passed criterion for understanding gender labels for others and for themselves. Although the findings were not entirely consistent, the patterns clearly suggest cognitionbehavior links. Despite the reduced variance for gender labeling and identity in this sample, 5 out of 10 of the correlations were significant (labeling and identity correlated with knowledge of gender stereotypes of clothing and with toy preferences; gender identity correlated with peer preferences), and 1 was marginal (labeling correlated with stereotype knowledge of toys). All correlations were in the direction suggested by cognitive theories.

Furthermore, although not a longitudinal data collection, Martin and Little's (1990) article examined variations in developmental patterns to determine how many children showed evidence of high levels of gender labeling while not yet showing either strong gender-typed preferences or stereotype knowledge versus the reverse pattern of having high levels of stereotype knowledge (or preferences) without understanding gender labeling. For both analyses, virtually every child (98\%-100\%) fell into one of the predicted stages, and few to none of the children showed the unexpected pattern of having strong gender-typed preferences (or stereotype knowledge) but not being able to accurately label the sexes. For instance, $53 \%$ of the children scored high in both gender understanding and sex-typed preferences and $33 \%$ of the children had high levels of accuracy in understanding gender labels but did not yet show evidence of having strong sex-typed preferences. Furthermore, only $2 \%$ showed the reverse, nonpredicted pattern of having strong sex-typed preferences but little gender understanding. These patterns suggest that young children develop their ability to discriminate and label the sexes before they develop many behavioral preferences and before they develop extensive gender stereotypes.

Taken together, concurrent correlations provide reasonably clear evidence for a relation between gender labeling/identity as an organizer for gender-typed preferences and behaviors in young children. Although not every correlation was significant, the effect would likely be stronger if enough studies were conducted to perform a meta-analysis. The problem with the concurrent data, of course, is that conclusions cannot be drawn about the nature and direction of a cause-effect relationship. For instance, the patterns identified above do not tell us precisely at what age gender labels emerge and how they exert their influence; instead, they only suggest a developmental trend. Furthermore, the concurrent correlational evidence does not preclude the possibility that children will also show gendered behaviors early in development.

A second kind of data is much more persuasive with respect to directionality - namely, longitudinal analyses showing that gender labeling emerges earlier than certain gender-typed behaviors. The most powerful demonstration of this effect was reported by Fagot and Leinbach (1989). This study involved a longitudinal examination of the development of gender labeling and observed gender-typed behaviors in children from 16 months to about 4 years of age. Children were tested once a month on a gender labeling task until they passed it. Early labeler boys and girls, who began labeling by 27 months of age, showed increased levels of gender-typed play from the first assessment to the toddler assessment at 27-28 months of age, whereas the other children did not show significant changes. Ideally, more longitudinal research would be useful for identifying when and how gender labels influence children's behavior.

In short, the data supporting a link between gender labeling/ identity and gender-typed preferences and behaviors appear to be strong and consistent. Studies examining this relation in young children have typically found significant correlations among most measures, and such relations may even be found in slightly older children. It is interesting that relations with peer preferences appear to be stronger than with toys, possibly because children initially want to find out more about other children who they think are like themselves. Furthermore, longitudinal and developmental analyses suggest that labeling/identity understanding typically precedes gender-typed preferences and behaviors, although exceptions to this pattern exist. Such data are consistent with the idea that gender labeling acts as a cognitive organizer for behavior. Exactly how these cognitions work to influence behavior and other aspects of gender development are important questions that still need to be addressed.

\section{Gender Stereotype Knowledge as an Organizer of Gender Development}

From a cognitive perspective, children's growing knowledge about what boys and girls like and how they differ is expected to influence and guide children's own interests and behaviors. Early formulations of gender schema theory suggested that, in young children at least, there were relatively straightforward associations between knowledge and behavior/thinking, although later versions were modified to consider some of the conditions that moderate the influence of knowledge on behavior (see Martin, 2000; Martin et al., 1995). Below we review two lines of evidence concerning the links between stereotype knowledge and behavior. Surprisingly little research directly assesses these links, and there are many methodological difficulties involved in conducting research on this topic (see Huston, 1985; Martin, 1993; Signorella, 1987).

Correlational studies of stereotype knowledge and behavior links. The most commonly cited evidence concerning knowledge-behavior links have been correlational studies, often 
conducted to assess links at the most global level, namely, between children's overall level of gender stereotype knowledge and their overall level of gender-typed behavior. The evidence from these studies is mixed, and there are many methodological challenges in conducting these studies (see Martin, 1993). Also, very few studies have tackled the most relevant issue-whether specific knowledge about which sex is more likely to do a particular behavior (or who they think should do this more often) relates to the likelihood of children engaging in that behavior. Thus, there is little direct evidence relevant to this issue.

Although the evidence is limited, careful analyses of the findings and the theoretical arguments have elucidated the complexities involved in understanding the role of stereotype knowledge in guiding behavior. Specifically, the most recent reviews of this issue (Aubry, Ruble, \& Silverman, 1999; Martin, 2000; Ruble \& Martin, 1998) suggested that a dismissal of gender knowledgebehavior links would be premature for a number of reasons.

First and foremost, even within cognitive theories, gender stereotype knowledge is considered to be only one of many factors (e.g., toy attractiveness, social desirability, personal skills, familiarity) likely to affect children's decisions about what they like and what behaviors they choose to engage in. Just because a girl learns that "dolls are for girls" and "trucks are for boys" does not mean that she will always choose a doll over a truck when given a choice. For instance, toy attractiveness influences children's choices. Unfortunately, many tests of the relation between knowledge and preferences involve measures in which the attractiveness of items is not equated or taken into account. For example, many studies used the Sex Role Learning Inventory (Edelbrock \& Sugawara, 1978), a measure that includes chores such as ironing and sweeping that could potentially dilute the relationship because of their unpleasant quality. In addition, children's motivations (e.g., how important it is for them to appear feminine) and attitudes (e.g., how strongly they believe that males and females should behave differently) also affect the link between knowledge and behavior (Signorella, Bigler, \& Liben, 1993). Hence, a one-to-one correspondence would not be expected. Nonetheless, several studies have found significant (though weak) correlations between stereotypic knowledge and behavior/preferences (Aubry et al., 1999; Coker, 1984; Serbin, Powlishta, \& Gulko, 1993). Children's beliefs about who boys and girls like to play with have also been found to relate to their stated preferences for same-sex and othersex playmates, as well as to their actual play preferences as observed over 6 months on the playground and in the classroom (Martin et al., 1999).

Second, there are many possible patterns of influence of stereotype knowledge on behavior, making relations difficult to detect in correlational studies. Consider these possibilities. Some children may perfectly follow stereotypic beliefs by approaching own-sex toys and avoiding other-sex toys. Other children may avoid counterstereotypic activities and toys but not feel compelled to engage in stereotypic ones. For instance, a boy who holds the stereotypic belief that "boys play with cars" may not play with cars because he recognizes that not all boys play with cars. However, he would still be surprised if he saw a girl playing with cars, and he may do many other "boyish" things. A one-to-one correspondence between stereotypic knowledge and behavior is certainly not predicted by cognitive theorists nor found in examinations of human behavior. Furthermore, the potential of several different patterns that all broadly cohere to the overarching notion that children follow stereotypes hinders the likelihood of finding relationships using simple correlations, as is typically done.

Third, research on stereotype development suggests that stereotype knowledge is often inadequately assessed (Liben \& Bigler, in press). With young children, assessments of gender knowledge are often far more challenging than assessments of gender preferences (Aubry et al., 1999). For example, several studies suggest that sorting tasks are poor indicators of what preschoolers know about logical rules (e.g., Zelazo, Reznick, \& Pinon, 1995). Thus, young children may actually know more about the gender appropriateness of toys than is evident in their performance on a gender knowledge sorting task (e.g., Weinraub et al., 1984). Furthermore, it is very difficult to assess nonverbal stereotype knowledge, although some researchers have recently developed methods of collecting these sorts of data. In addition, measures of knowledge and behavior often use different formats and items. The stereotype measure may ask about adult roles and chores, whereas the behavior observed may involve toys. Surprisingly, very few studies have examined children's knowledge and preferences for the same items. Furthermore, until recently (see Liben \& Bigler, in press), virtually all the studies to date have examined children's gender cognitions about toys and/or activities but not other aspects of behavior. Children's gender-related expectations and knowledge about the more subtle aspects of behavior may develop somewhat later than simple toy stereotypes, and so the latter's influence may be more easily measured. Researchers also have not been sensitive to distinguishing among children's knowledge of cultural stereotypes versus assessing their own personal stereotypes about the sexes. It may be that personal stereotypes influence children's own behavior more than cultural stereotypes.

Fourth, developmental level has not been carefully considered in examining these relations. For example, finding individual differences may be precluded by the very high levels of knowledge that most children exhibit about gender roles after the age of 5 years (using most developmental measures of gender stereotypes). In addition, the most logical time to look for the effects of knowledge is when it is first being acquired. Does the emerging knowledge that, for example, tea sets are for girls subsequently lead girls to increased play with tea sets and lead boys to avoid them? In one study, such relations were found for concrete items, such as a hairbrush and a shovel, only for children 4-6 years of age, whereas for abstract characteristics, such as gentle or helpless (which are learned later), relations were observed primarily for children 6-8 years of age (Aubry et al., 1999). These results indicate that the effects of gender schematic knowledge on preferences are more readily discernable when such schemas are emerging. An additional problem with detecting this relation is that it occurs over time-assessments at a single point in time may not reveal a true relation. A lag between the emergence of knowledge and its associated preference would be especially likely when it means taking on something unattractive, such as chores, or when it means giving up something that is attractive, such as dressing up. In support of this idea, the Aubry et al. (1999) study found that many relations between knowledge and preferences involved such lagged effects, especially for avoidance of other-gender items.

Experimental studies of stereotype knowledge and behavior links. A whole line of experimental research illustrating the influence of gender stereotypes on children's behavior and think- 
ing often has not been considered in the debate about the cognitive underpinnings of gender development. This research provides support for the idea that when all other influences are stripped from the situation, children's ideas about gender stereotypes do indeed influence their behavior. These studies grew out of the recognition of the problem in the correlational studies-namely, assessing the role of cognition on behavior has been confounded by children's prior experience with toys and activities. An adequate test requires disentangling the influence of children's prior history with toys and activities from the influence of their cognitions about those toys. Research strategies involving novel toys and novel activities have been successful in this regard.

In a recent review of these studies, Martin and Dinella (2001) describe in detail the many studies using this technique. The most striking aspect of these studies is the consistency of the findings: Gender knowledge influences children's behavior, their motivation and interests, and their memory for information. In a typical novel toy study, children are provided with novel non-gender-typed toys that are given labels as to their gender typing ("I think boys like the things in this box better than girls do") and label-toy combinations are varied to ensure that no particular feature of the toys influences children's behavior. After naming and labeling toys, children can play with the toys while the experimenter sits off to the side. Children's play behavior and their memory for the information (names and labels) is assessed. When this technique was used with preschoolers, Bradbard and Endsley (1983) found a powerful influence of gender stereotypes on exploration in that children played more with own-sex-labeled toys than with other-sexlabeled toys, and both-sex toys were intermediate. Children's memories also showed an influence of gender labels: Children recalled more names of own-sex-labeled toys than other-sexlabeled toys and both-sex toys were intermediate (Bradbard \& Endsley, 1983). Several other studies have demonstrated similar patterns of results on children's behavior and preferences (e.g., Bradbard, Martin, Endsley, \& Halverson, 1986; Martin et al., 1995). Furthermore, when the influence of gender stereotype labels and sex of models have been directly compared, gender labels have been found to influence children's behavior more than models' sex (Masters, Ford, Arend, Grotevant, \& Clark, 1979).

Gender stereotyping labels also have been demonstrated to influence children's motivation, accuracy, and expectancies for success (Davies, 1986, 1989; Gold \& Berger, 1978; Hargreaves, Bates, \& Foot, 1985; Stein, Pohly, \& Mueller, 1971). The influence of gender stereotype labels on children's motivation was well documented in a classic and often-cited study involving children's performance and liking of a novel throwing game, Mr. Munchie, which was given gender-typed labels (e.g., "the game is for girls, like jacks"). Both boys and girls liked the game better and performed better when they believed the game was meant for children of their own sex or was for both sexes rather than when they believed it was meant for the other sex (Montemayor, 1974). In some cases, knowledge may primarily affect avoidance of othersex activities. When the manipulation of appropriateness was done by showing same- or other-sex models playing with the toy (Ruble et al., 1981), for gender constant children, learning that the game was gender "appropriate" did not lead children to like the toy relative to perceiving it as neutral, but learning that the game was "inappropriate" led to increased rejection.
Experimental studies also support the position of cognitive theorists that gender-typed labels play an important role in influencing children's behavior through their effects on attention and memory. Children are assumed to remember basic information about activities associated with each sex; however, they are expected to show better memory for in-depth, script-like information about own-sex-relevant activities as compared with other-sexrelevant activities (Boston \& Levy, 1991). Limited competence in other-sex activities (i.e., not knowing how to do an activity) may then affect the likelihood of these activities being performed. Several studies using novel objects or activities have illustrated that children's memory for information depends on whether they believe it is relevant for their own sex or not (Bradbard \& Endsley, 1983; Bradbard et al., 1986; Martin et al., 1995). Only one study that we know of has failed to show this type of pattern (in this case, information was linked to gender by the sex of the models performing the activities), possibly because memory testing was done immediately rather than after a time delay (Bussey \& Bandura, 1984). In addition, if memory for other-sex information is impaired, no amount of reward should be able to increase the likelihood of performing a behavior that requires this knowledge. Findings from the Bradbard et al. (1986) study suggest that memory for other-sex information was not enhanced with very attractive incentives (over no reward). Although a one-time incentive may not have been powerful enough to override a long-term history of gender-typed behavior, the study did address one reason why children may not engage in other-sex activities, and it clearly illustrates how competence can be undermined by gender stereotypes.

A potential criticism of the experimental studies is the demand characteristics involved in the labeling of the toys and activities. Children are often told that most girls or most boys like something or do well at a particular task, and they may feel pressure to conform to these views. However, in several studies in which the labels were subtle and only indirectly related to gender, effects of the labels continued to be evident (e.g., Davies, 1986, 1989; Hargreaves et al., 1985). For example, Hargreaves et al. (1985) found that children's performance on a motor steadiness task was influenced by subtle labels that suggested gender associations. Some children were told, "This is a test to see how good you would be at mechanics or at operating machinery," and the others were told, "This is a test to see how good you would be at needleworksewing and knitting." Both sexes made fewer errors on the task when it was interpreted as being sex-appropriate. Furthermore, in studies in which demand characteristics have been minimized by having different experimenters provide the labels and do the testing, gender labels still exerted a powerful force on children's toy preferences (Martin et al., 1995).

The pattern of consistency in these experimental studies is striking, but a few studies failed to find the influence of gender labels. One study did not find gender labeling effects in a novel game (Herzog, Enright, Luria, \& Rubin, 1982) and one found gender labeling effects for older but not younger children (Bradbard et al., 1986). Although the exact reasons for these failures to replicate are not clear, Herzog et al. (1982) suggested the possibility that children are not simply passive recipients of information. Children may construct their own labels, and these may conflict with externally imposed labels. Their results provide support for this notion: Of the 160 children interviewed in their study, 
about $70 \%$ said they used their own ideas about toy appropriateness (not the experimenter-supplied labels) and a small percentage forgot the labels. Only $23 \%$ of the children in this study could potentially show the effect of experimenter-assigned labels. It is important to note that other research on gender stereotype labels illustrates that children must remember the gender-typing labels for them to be effective (Martin et al., 1995).

Children's own ideas about gender stereotyping, even when idiosyncratic, have been documented to exert powerful influences on their behavior. In an early novel-object study (Bradbard \& Endsley, 1983), one young boy informed the experimenter that he thought there was a mistake: One of the toys that was labeled as being for girls, he thought was for boys. On the basis of this child's comments, two studies were conducted to assess the extent to which children would infer that their own preferences are also preferences shared by other members of their sex (Martin et al., 1995). In these studies (Studies 1 and 2), young children were given novel objects with no gender stereotype labels, and the children were asked how much they liked each toy. The children then predicted how much girls would like the toy and how much boys would like the toy. Even though no sex differences were apparent in toy preferences, children assumed that other same-sex children (though not other-sex children) would like the same toys as they did and would dislike the same toys they did.

The idea that children may reject the experimenter-supplied label has some interesting implications for the current debate. Children may enter such experimental situations with preformed ideas about what elements of activities connote male versus female appropriateness. Thus, in some cases, failures to show labeling effects may actually be evidence of the influence of children's own gender schemas. Future research needs to examine more directly this interpretation.

From the experimental studies of modeling, the conclusion can be drawn that the potential for models to influence children's behavior exists, but one cannot conclude that these studies reflect what actually happens during development. Similarly, the genderstereotype-labeling studies are not a perfect reflection of children's everyday lives, and they do not directly show the influence of a well-developed, stored gender schema. However, these studies do provide a controlled setting in which researchers can assess the influence of gender knowledge on children's exploration, attention, motivation, and behavior. Essentially these studies illustrate that when toys are stereotyped, either with overt or covert cues, children often respond according to whether the toy is appropriate or inappropriate for their own sex. Overall, these studies show that stored gender stereotypic knowledge could act in a schema-like way, because children will respond to such knowledge when it is accessible.

Hence, the picture that emerges from several lines of research suggests that children's behavior is organized and motivated by gender stereotypes. Few studies have been done to examine the direct links between children's gender stereotypes and their behavior, and interpretations of even those studies are difficult because of a variety of methodological limitations. However, in several studies that used similar items for knowledge and preferences, the two were related. In addition, the results of experimental studies suggest that knowledge of gender stereotypic information guides children's behavior. Future research in this area may find that links between children's stereotypes and their behavior are more evident when stereotypes are salient, either chronically or because of children's being in a particular situation (e.g., with peers). Discrepancies among studies may be due to variations in stereotype salience. In addition, some sex differences in behavior may be due to differences in the accessibility of gender schemas and to the felt pressure to adhere to them (Liben \& Bigler, in press; Ruble \& Martin, in press). These views are consistent with the arguments originally made by gender schema theorists and with recent ideas about how variations occur in the use of gender stereotypic knowledge (Hannover, 2000; Martin, 1993, 1999, 2000).

\section{Summary}

When all of the evidence is reviewed concerning the roles of cognitive structures, the predictions from cognitive theories fare quite well. The evidence from many studies using a wide range of methods suggests that gender cognitions play a significant role as organizers of gender development. Children develop an awareness of gender labeling and identity at an early age, and this awareness relates to their peer preferences and to some of their toy choices and social behaviors. Few studies have directly assessed gender stereotypes as organizers of children's behavior, and even fewer have conducted studies in which confounding methodological problems have been considered. Nonetheless, the experimental evidence is clear: Gender stereotypes about activities and toys influence children's behavior, motivation, and memory.

\section{Early Origins of Gender Development}

Cognitive explanations for early gender development were first brought under scrutiny by an article published in 1985 describing the time line of gender development (Huston, 1985). The concern was that cognitive explanations of the earliest origins of gender development may be untenable because gender differentiation in behavior was observed prior to even basic forms of gender knowledge such as gender labeling. This time line was based on evidence from many studies indicating that children's abilities to label the sexes either verbally or by recognizing labels emerge around the age of 2 to $2 \frac{1}{2}$ years (e.g., Leinbach \& Fagot, 1986; Weinraub et al., 1984). Gender identity understanding had not been assessed in many studies, although some evidence indicated that this understanding emerged by about 26-31 months of age (Weinraub et al., 1984). If cognitive mechanisms play a role in early development, one might expect that verbal gender labeling would precede children's gender-typed toy preferences and behavior; however, the evidence at the time was interpreted as not supporting this expectation. Instead, toy preferences and some forms of behavioral sex differences were found to emerge earlier than labeling, generally between the ages of 14 months and 2 years (depending on the behavior and sex of child; for discussion, see Huston, 1985). However, these early sex differences (before 24 months old) have been documented in only a limited number of studies, often with parents present (who may influence children's toy choices), and gender differences have been apparent on only a few toys and behaviors. Specifically, early gender differentiation tends to be expressed as in girls' preferences for dolls and boys' preferences for transportation toys (e.g., Caldera, Huston, \& O'Brien, 1989; Roopnarine, 1986; Weinraub et al., 1984). Furthermore, early sex 
differences have been reported for some aspects of behavior, such as activity level and forbidden play (e.g., P. L. Smith \& Daglish, 1977).

Although these few studies suggest that there may be some early gender-differentiated behaviors, much of the available research in which children are observed in natural or laboratory settings suggests that gender-differentiated behavior is more clearly evident around the age of 2 years old or soon after, and that it is apparent for a relatively narrow range of activities and behaviors (e.g., Etaugh, Collins, \& Gerson, 1974; Fagot, 1974; Weinraub et al., 1984). Even for children at the age of 2 years old, however, not all studies confirm the pattern of gender-differentiated behavior (e.g., Blakemore, LaRue, \& Olejnik, 1979, boys only; Fein, Johnson, Kosson, Stork, \& Wasserman, 1975, girls only; Perry, White, \& Perry, 1984). Furthermore, individual differences in children may account for some of the inconsistencies in the findings: Fagot and Leinbach (1989) found that children who were early gender labelers showed more gender-differentiated behavior with toys than late gender labelers.

As we suggested above, these observations about the time line for development do not in themselves invalidate the influences of cognitive milestones such as gender labeling and gender constancy. When early differentiation in behavior occurs, it may be related to biological influences, parental reinforcement, and/or to familiarity with toys in the home. Another intriguing possibility is that earlier forms of gender knowledge may exist that are simply not being captured by the kinds of gender labeling and identity measures used in the above studies. It is extremely difficult to assess such understanding in preverbal children; however, in the last 5-10 years, promising efforts have been made to assess gender concepts in very young children. A number of researchers have cleverly modified infant testing procedures to begin looking at the earliest origins of gender development. In the following sections, we describe some of the research that has been conducted with infants and toddlers to examine their emerging understanding of gender. The new time line of gender development is quite different than the one outlined by Huston in 1985: Evidence suggests that rudimentary forms of gender understanding may be present remarkably early, even before gender-differentiated behavior is obvious (see Table 1). On the basis of the findings from these new lines of research, the picture of the earliest aspects of gender development needs to be significantly revised.

Table 1

Time Line for Early Gender Development

\begin{tabular}{|c|c|}
\hline Age & Gender-based knowledge and perception \\
\hline \multicolumn{2}{|l|}{$0-5$ months } \\
\hline $6-8$ months & $\begin{array}{l}\text { Discriminate voices of males and females (C. L. Miller, 1983) } \\
\text { Habituate with one category of faces (Younger \& Fearing, 1999) } \\
\text { Use hairstyle to discriminate faces by sex; boys only (Pakizegi, 1984) } \\
\text { Intermodal associations for dynamic displays of the sexes (Walker-Andrews et al., 1991) }\end{array}$ \\
\hline 9-11 months & $\begin{array}{l}\text { Discriminate male and female faces (Cornell, 1974; Leinbach \& Fagot, 1993) } \\
\text { Use male and female categories simultaneously in habituation (Younger \& Fearing, } \\
\text { 1999) } \\
\text { Intermodal association for female faces and voices (Poulin-Dubois et al., 1998) } \\
\text { Detect correlations among faces of men and women and gender-related objects (Levy \& } \\
\quad \text { Haaf, 1994) }\end{array}$ \\
\hline $\begin{array}{l}12-14 \text { months } \\
15-17 \text { months }\end{array}$ & Intermodal associations for male faces and voices (Poulin-Dubois et al., 1998) \\
\hline 18-20 months & $\begin{array}{l}\text { Gender-typed visual preferences and stereotype knowledge; girls only (Serbin et al., } \\
\text { 2001) } \\
\text { Recognize labels associated with faces, especially for girls (Poulin-Dubois et al., 1998) } \\
\text { Metaphoric associations with gender (Eichstedt et al., in press) }\end{array}$ \\
\hline
\end{tabular}

$21-23$ months

24-26 months Onset of nonverbal, verbal gender labeling (26-31 months; Weinraub et al., 1984)

Gender labeling (2-21/2 years; Leinbach \& Fagot, 1986)

Receptive labeling of sex of self (24-30 months; Sen \& Bauer, 2001)

Longer looking time for gender-inconsistent activities (Serbin et al., in press)

Generalized gender-typed imitation; girls only (Poulin-Dubois et al., 2002)

Elicited imitation of gender-related sequences (25 months) for boys (Bauer, 1993)

Gender-typed toy category awareness (Levy, 1999)

27-29 months Gender labeling (majority; Etaugh et al., 1989)

30-32 months Gender labeling (Thompson, 1975)

Nonverbal gender identity (majority; Weinraub et al., 1984)

Generalized imitation of masculine activities for boys (Poulin-Dubois et al., 2002) 


\section{Gender Category Development in the First Year of Life}

One of the gender development topics most amenable to testing in infancy is when children distinguish between the sexes. Discovering this point in development should signal when gender can be used categorically. Cognitive psychologists suggest that categorical knowledge is illustrated when infants respond to members of one category in similar ways and respond differently to members of other categories.

Habituation paradigms offer a plausible index of categorization abilities in infants. Studies using a variety of stimulus materials in standard habituation paradigms have suggested that the ability to categorize is present by about 6 months of age (Haith \& Benson, 1998). The studies that have used similar methods to examine infants' ability to discriminate gender categories support the hypothesis that infants are capable of making categorical distinctions in the first year of life. For example, C. L. Miller (1983) habituated 2- and 6-month-old infants to one voice category (male or female) and then presented either the other voice category, a new voice from the same category, or no voice change. She found that 6-month-olds but not 2-month-olds demonstrated discrimination that was specific to a between-category change, thereby providing evidence that infants show categorical responding to female and male voices by 6 months of age. Using a habituation paradigm with varying physical features (e.g., hairstyles, clothing), Pakizegi (1984) found that certain features such as short hairstyles were more salient and influenced dishabituation more than variations in body shape and clothing for 8-month-old boys. In a visual assessment study designed to investigate discrimination of the sexes, infants were presented with faces of members from one gender category and then tested on faces from the other category. The findings showed categorical recognition of male and female faces by $9-12$ months of age; infants appeared to use hairstyles and hair length and clothing styles to make these discriminations (Cornell, 1974; Leinbach \& Fagot, 1993; see Katz \& Kofkin, 1997).

The habituation studies show that prior to 1 year of age, infants can notice a difference when an instance of a new category is introduced following a familiarization phase with another category. These data suggest that infants form categories, including gender categories, well before language emerges (Courage \& Howe, 2002; Haith \& Benson, 1998). A crucial question then becomes, at which point are infants capable of forming both sex categories - female and male-and holding them in mind simultaneously? To address this question, faces from both categories must be presented together during familiarization. In a recent study, 7-month-old and 10-month-old infants were familiarized with faces of men and women (Younger \& Fearing, 1999). During testing, they were shown two other faces-either a novel gendertypical male and a gender-ambiguous male or a novel gendertypical female and gender-ambiguous female - along with a teddy bear to ensure that decreases in looking time are specific to the familiarized category and not simply to boredom. Seven-monthold infants generalized habituation to both the gender-typical and gender-ambiguous faces, suggesting that they had formed one category that included all the familiarization items, regardless of sex. In contrast, the 10-month-olds generalized habituation to novel faces that were consistent with the categories they were familiarized with (i.e., the gender-typical faces) and attended more to the faces that were inconsistent with the familiar categories (the gender-ambiguous faces). This pattern suggests that the 10-montholds treated the familiarization faces as members of distinct gender-based categories. It is interesting that not all the faces had clearly gender-typed hairstyles, suggesting that infants also used other cues to make the discriminations between the sexes. Thus, it appears that by 10 months of age, infants are capable of holding both gender categories in mind while making some types of judgments.

Infants' categorical use of gender is illustrated as well in studies that assess their intermodal knowledge. For instance, infants may be presented with a female voice saying, "Look at me," and photographs of a male and a female. If infants understand that a female voice is associated with a female face in a photograph, then they should be more likely to attend to the female photograph than to the male one. In several studies, Poulin-Dubois, Serbin, Kenyon, and Derbyshire (1994) assessed intermodal knowledge in infants and found that this knowledge is reliably demonstrated in 9-month-old infants if the visual displays are very stereotypic female faces. By the age of 12 months, infants begin to show the same intermodal knowledge of males. When visual displays have been presented dynamically (on videotape), infants may discern intermodal associations between sex and voices at an even earlier age, around 6 months of age. However, intermodal knowledge may be fragile and fleeting in this very young age group: The infants failed to abstract the intermodal relations on $50 \%$ of the trials (Walker-Andrews, Bahrick, Raglioni, \& Diaz, 1991).

Toward the end of the first year of life, infants also begin to demonstrate the early foundations for developing associations between faces (of women and men) and gender-related objects (e.g., hammer, scarf). Specifically, Levy and Haaf (1994) found that 10-month-old infants showed increased attention to new faceobject pairs only when the face of one sex was paired with an object previously associated with the other sex. That is, infants appeared to recognize the association between gender categories and objects. As with any habituation study, it is difficult to ascertain from the study whether infants developed ad hoc categories or whether any of these associations had already been learned. Nevertheless, these data are suggestive that infants may have the capacity to form primitive stereotypes early in life.

Although the conclusion could be drawn from these studies that infants in their first year develop rudimentary categorical knowledge of the sexes, caution must be used in assessing the results of discrimination studies. In the earliest habituation studies, it was not clear whether infants may have established basic categorical information about the sexes or whether these are ad hoc categories formed during the time of testing. The most recent studies, however, suggest that infants do hold gender categories in mind for at least some time, rather than simply forming them ad hoc. Furthermore, the data suggest that sometime between 6 and 12 months of age, children become capable of distinguishing between males and females in a categorical manner. It is not clear, however, why some assessments of this categorical knowledge provide more straightforward evidence than others.

Although the evidence is preliminary, studies of gender categorization suggest that infants parse the social world around them, much in the same way that they parse other types of information. An importance mechanism in language learning, for instance, is that infants use the statistical regularities of language as a way to organize and make sense of continuous streams of phonemes (e.g., 
Saffran et al., 1996), providing them with ways to chunk phonemes into words and phrases. A reasonable hypothesis is that the same processes that infants use in other aspects of learning are involved in learning about the sexes-that is, infants are noticing and registering regularities of actors and actions.

The rudimentary associative networks infants may form about the sexes may not carry the same conceptual or affective associations that would characterize older children's or adults' concepts of the sexes, although this possibility has not yet been examined. Early gender schemas may consist largely of salient cues, many of which are physical characteristics (e.g., hair length, dress style, height, facial hair) that are correlated with gender group membership. Nonetheless, recognizing these correlates of sex may provide infants with ways to chunk their social worlds because they can recognize (in many cases) who is a male and who is a female; thus infants have, in essence, the building blocks in place for forming larger and more extensive networks of associations with gender. Additional research is needed to replicate the pattern, however, the finding that infants were able to associate stereotypic objects with the sexes (e.g., Levy \& Haaf, 1994) suggests that they are developing the capacity to attend to what the sexes are doing and may in certain circumstances make associations with these more temporal-constrained and fleeting aspects of sex differences.

Although infants' early categories-for gender and for objects-are largely based on perceptual discriminations, even very young infants appear to simultaneously abstract more global properties of categories, thus showing some evidence of conceptual categories (Mandler \& McDonough, 1996; McDonough \& Mandler, 1998). No resolution has come from disagreements about the course of perceptual versus conceptual development. Conceptual categories may be built on perceptual categories or conceptual and perceptual categories may develop along different and possible tandem trajectories (Courage \& Howe, 2002). Taken together, the research on infants' object categorization abilities and, in particular, the evidence on gender categories converge on the idea that infants have a capacity to develop at least rudimentary gender schemas within the first year of life.

\section{Gender Category Development in the Second Year}

Young infants' capability of noticing statistical regularities appears to continue to be the engine driving gendered learning in the second year. Studies using a variety of paradigms suggest that infants' knowledge of attributes associated with gender categories increases substantially during the second year. Studies involving assessments of intermodal knowledge show that by 18 months of age, infants have started to associate verbal gender labels (e.g., lady, man; Poulin-Dubois, Serbin, \& Derbyshire, 1998) with the categories of faces, although girls tend to show better labeling at this age (Poulin-Dubois, et al., 1998).

Studies using sequential visual attention paradigms also suggest that infants at this age may be aware that toys are associated with faces of the sexes. In this procedure, infants were presented with faces of females and males and pictures of male-typical and female-typical toys (sometimes with faces first, other times with toys first) while the amount of time they spent looking at the matching and mismatching pairs was assessed (Serbin, PoulinDubois, Colburne, Sen, \& Eichstedt, 2001). For instance, after being shown a doll and hearing a voice say, "Where's my toy?" a face of a girl and a boy are shown. Looking time should indicate which face children think is paired with the toy. During control trials, only the toys are presented, allowing for the assessment of visual preferences. In the Serbin et al. (2001) study of 12-, 18-, and 24-month-old infants, some evidence of gender category-attribute associations was found. Although the results varied depending on whether the faces or toys were presented first, gendered associations were evident in girls by 18 months of age, but boys did not associate faces with toys at that age or at 24 months of age. Thus, this study implies that children's ability to develop associations is in the process of developing in the first 2 years of life but that boys' knowledge may develop more slowly than girls'.

Another method used to study infant concepts and preferences involves assessing infants" "surprise" when looking at expected and unexpected events. The idea is that infants will look longer at novel and surprising situations. In one study (Serbin, PoulinDubois, \& Eichstedt, in press), infants 24 months of age were shown pairs of males and females engaged in the same activity, with some of the activities being gender consistent and some being inconsistent with gender stereotypes. Children's attention to the pictures was recorded to assess whether they would look longer at the gender-inconsistent pairings than at the gender-consistent pairings. For instance, would children show more surprise and look longer at a man putting on lipstick than a woman putting on lipstick? The results showed that infants paid more attention to the incongruous activity of a man putting on make-up, whereas the other activities did not garner extra attention. According to parents' reports of children's exposure to various activities (and which sex was observed performing the activities), the act of putting on make-up was the most stereotypic of all of the ones tested. The limitation of this study was that these toddlers were older than the subjects typically used in a "surprise" paradigm. Hence, they may have become bored or inattentive during testing. A more active, engaging task might be required to better address toddlers' knowledge of gender stereotypes. Nonetheless, the findings suggest that toddlers have formed associations between some activities and gender groups and that they look longer at a person engaged in a gender-inconsistent activity.

Generalized imitation procedures also have been used to assess whether a child can generalize a concept to a new situation. In a series of studies using this method (Poulin-Dubois, Serbin, Eichstedt, Sen, \& Beissel, 2002), children were shown an activity using a gender-neutral doll (a monkey) and then were given activity props and a male and female doll so that they could imitate the activity. At 24 months of age, girls were more likely to choose a male doll to demonstrate the masculine activities (e.g., fixing car, shaving) and a female doll to demonstrate the feminine activities (e.g., make-up, rocking baby, vacuuming). For boys, no preference for using one doll over the other was apparent. Why did girls, but not boys, show gender stereotype knowledge? The only difference in exposure to these activities was that boys had less experience than did girls observing their mothers apply make-up and thus may not have yet learned this association. Furthermore, more boys were dropped from the study for lack of compliance, possibly because they did not want to imitate any behavior involving dolls.

In their next study, which involved somewhat older children, Poulin-Dubois et al. (2002) found that boys at 31 months of age showed a preference for using a male doll to imitate masculine activities but the boys did not show any preferences to use female 
dolls for the feminine activities. Differential learning of masculine versus feminine activities may be due to the lack of genderspecific exposure these boys had to the feminine activities. Parents reported that many of these supposedly feminine activities were, in fact, done approximately as often by males as females in their homes, although they did report the masculine activities were done more often by males. Thus, the boys' pattern of responding in this study may reflect a sensitivity to the actual correlations between sex of actors and activities experienced within their homes.

Given that children construct gender stereotypes at least in part from what they observe in their social environments, it is not surprising that conventional gender stereotype knowledge, such as the association between men fixing cars and women putting on make-up, may be dependent on actual experiences in their homes. However, gendered associations go beyond these types of conventional associations. As Bem (1981) described, gender schemas are laden with metaphorical associations. Women are associated with softness and roundness; men with sharpness, hardness, and roughness. Such associations may be derived from inferred correspondences between gender groups and other categories of information, such as between voice pitch or the different textures or colors in clothing and roughness or softness (Leinbach, Hort, \& Fagot, 1997). They may also represent prototypic representations or averages of the features of the exemplars within the category, a process that has been shown to begin in infancy (Haith \& Benson, 1998). Such metaphorical associations play an important function in conceptual development because they allow the perceiver to build schemas around themes and dimensions rather than around limited associations between specific items (Leinbach et al., 1997).

Along these lines, recent research suggests that by 18 months of age, toddlers have begun to form masculine metaphorical associations, linking fir trees, bears, and the color blue with males; feminine metaphorical associations were not found to be significant (Eichstedt, Serbin, Poulin-Dubois, \& Sen, in press). It is interesting that toddlers made these metaphoric associations with sex but did not make links among more traditional and commonly associated items such as associating males with fire hats or hammers. Speculation has been offered that traditional stereotyped items may be learned differently than metaphorical knowledge. Also, masculine metaphorical associations may be learned particularly easily because they involve projecting men's physical features (such as their size, angularity, and low-pitch voices) to the objects whereas the feminine ones are more abstract (e.g., knowing a heart represents love and nurturance). In fact, Leinbach and her colleagues (1997) argued that knowledge of gender metaphors may be an organizer for other types of gender knowledge acquired during the early years.

\section{Elicited Imitation: Evidence of Selective Memory}

Given the difficulties of assessing infants' capabilities, few researchers have tackled the question of whether infants show differential memory for gender-congruent events. However, elicited imitation tasks can be successfully used to assess children's memory without requiring comprehension of complex verbal instructions or a verbal response (Bauer, 1993). In one study assessing elicited imitation of gender-related sequences in very young children, Bauer (1993) found that 25-month-old toddlers showed some evidence of using gender schemas. In the study, an experi- menter demonstrated a sequence of actions using props (e.g., diapering a teddy bear, shaving a teddy bear) and then asked the children to repeat the action immediately and then after a delay. Using a variety of measures, Bauer found that girls spent approximately the same amount of time imitating female- and malestereotyped sequences, whereas boys spent more time imitating the male-stereotyped sequences. Bauer concluded that boys showed evidence of using gender schemas by showing differential memory for own-sex tasks. The asymmetry in findings may have been due to the models being female (so girls assumed all activities were appropriate for them) or due to differences in perceptions about the appropriateness of engaging in other-sex activities.

\section{Preverbal Gender Identity}

Presumably, knowledge of attributes associated with gender categories should only affect infants' own preferences if they have some awareness of which category they belong to. When do infants become aware that they are girls or boys and that certain activities are more "appropriate" for them? This is a difficult question to answer. It is not clear what kind of nonverbal measure or set of measures would demonstrate conclusively that children are aware that they are boys or girls. One relevant set of findings comes from the self-recognition literature (Lewis \& Brooks-Gunn, 1979). Considerable research suggests that children can recognize themselves in mirrors and photographs as distinct from other children between 18 and 24 months of age (Asendorph, Warkentin, \& Baudonniere, 1996). Such an awareness seems likely to signal that children at this age might be capable of categorizing themselves along such dimensions as age and sex (Stipek, Gralinski, \& Kopp, 1990). Another potentially relevant set of findings comes from the social-referencing literature. A number of findings suggest that at about the same age that self-recognition is developing, children engage in active information seeking about what things mean and how they are supposed to behave (Baldwin \& Moses, 1996; Hornik \& Gunnar, 1988). Beginning at about 18 months of age, then, infants would appear to be developing the resources necessary for an active construction of self.

To our knowledge, no researchers have directly tried to assess gender identity between 18 and 24 months of age. A few studies have looked at younger children. One recent study included an impressive battery of measures to look at converging evidence regarding the development of "tacit" knowledge of gender (Campbell, Shirley, \& Heywood, 2000). Several possible indices of gender identity were examined in a longitudinal study of 40-50 (depending on the measure) children tested at 3, 9, and 18 months of age. One measure was self-recognition, using a visual preference paradigm. The child's own photograph was presented with a photograph of another same-sex, same-age baby. There was not a significant difference across age, nor an interaction with age, although an examination of Table 1 in the Campbell et al. (2000) article suggests that infants did look longer at their own picture at 9 and 18 months of age. Moreover, self-recognition was found at 18 months of age using the rouge test (Lewis \& Brooks-Gunn, 1979), consistent with other studies, as described earlier. Thus, it is important to be cautious about interpreting this apparent null effect. Only one visual preference trial of self-recognition was included at each age, and the variance was high. 
A second measure was visual preference for same-sex babies and children. Once again, no significant differences were found at any age. This kind of measure appears to show inconsistent findings in the literature. For example, Lewis and Brooks-Gunn (1979) reported that 16-18-month-old infants looked longer at photographs of same-sex children when compared with other-sex children in one study (Study 1) but not in another study that included infants about 6 months older (Study 2). It seems possible that infants are guided by certain concrete gender cues, such as hair length and dress, and variations in results may depend on how salient such attributes are made in the photographs.

A third and fourth measure involved looking at sex-congruent versus sex-incongruent toys and activities. Both boys and girls were found to look longer at male activities. These findings are difficult to interpret in terms of gender preference or knowledge, because the male stimuli were both more interesting and more clearly associated with boys. For example, male stimuli included a train, cars, climbing, and wrestling; whereas female stimuli included a dustpan, a toaster, whispering, and drawing.

Although the Campbell et al. (2000) study failed to show "tacit" gender identity in children under 18 months old, the various measurement limitations, probably inherent to studies with children of this age, make it difficult to draw a clear conclusion from this study. With a sample of slightly older children, Sen and Bauer (2001) used a receptive labeling task in which children were asked to choose a girl or a boy and within the mix of photographs were three of themselves. This task allows for a nonverbal assessment of gender labeling of others and can be used to determine the child's awareness of their own gender category. They found that the 24and 30-month-old children in the study knew the gender groups to which they and the others belonged.

In short, converging evidence suggests that gender identity may emerge between 18 and 24 months of age, but this hypothesis has yet to be directly evaluated. To date, researchers have had to draw inferences about infants' and toddlers' self knowledge on the basis of showing a preferential response either to males and females, to their own photographs, or to a category of toys or objects. Although inferences are drawn from differential looking time (or lack thereof), this behavior does not necessarily reflect "surprise" or "preference." Future research would benefit from new methodologies and direct testing of infants between the ages of 18 and 24 months.

\section{A New Time Line of Early Gender Development}

Taken together, these findings imply that young infants have rudimentary gender categories with the ability to form associations with attributes and activities associated with those categories, whereas older infants possess a fairly advanced level of knowledge about gender categories. Infants and toddlers develop gender categories and networks of gender-associated attributes well before they can verbalize such knowledge and well before many gendertyped preferences are observed in play behavior. A reasonably consistent pattern of support has been found for infants' abilities to discriminate and use gender categorically by the end of the first year of life. These distinctions are largely based on obvious physical features that are highly correlated with the sexes and serve to differentiate the groups visually (e.g., hairstyles, clothing). Not long after, children may develop metaphorical associations with gender and then begin to form gender stereotypes in which they associate the sexes with some activities and objects (especially girls). Not surprisingly, these early activity-object associations appear to be highly dependent on exposure within the home, possibly because they are more variable (i.e., less consistently stereotyped) in their associations with members of the gender groups than are physical features.

The obvious next question is whether such preformed categories and knowledge of gender-associated attributes affect infants' actual behavior. Do they also begin to exhibit approach and avoidance orientations toward gender-consistent and genderinconsistent objects and activities at around the same age or soon thereafter? That is, does preverbal knowledge influence preverbal behavior? This question is difficult to address for some of the same reasons described earlier with respect to the link between gender schemas and preferences and behaviors among older children: (a) Assessing knowledge may be more difficult than assessing preferences, and (b) infants may express preferences prior to knowledge about certain items because of familiarity in the home or other reasons, although this does not mean emerging knowledge would fail to have an impact on those preferences.

To our knowledge, only one study has examined both preferences and gender stereotype knowledge in young children, and conclusions are qualified by the above two limitations. In the Serbin et al. (2001) study described earlier, 18-month-old and 24-month-old girls showed more visual interest in the femaletypical toys (dolls) than did boys. Because girls were also found to show knowledge of pairing dolls with female faces by 18 months old, this finding provides at least indirect evidence of a link between knowledge and preferences for infant girls. Surprisingly, boys showed more visual interest in male-typical toys (vehicles) but did not show knowledge of pairing of vehicles with male faces. This finding suggests that boys' preferences for vehicles may emerge prior to their knowledge of the association between males and vehicles. Serbin et al. concluded that the cognitive and affective components may develop somewhat independently or in parallel and that these gradually become linked during early childhood to form a comprehensive schema with cognitive, affective, and behavioral components.

Although the relations between verbal gender labeling/identity and behavior in young children have been demonstrated, as described in the Basic Gender Understanding (Identity or Labeling) as an Organizer of Gender Development section, these links have seldom been tested in preverbal infants and toddlers. In Campbell et al.'s (2000) study of 3- to 18-month-olds, gender identity was found to be unrelated to children's visual gender-typed preferences, although as described earlier, measures of both gender identity and preferences were problematic. In future research, it may be productive to use methods similar to those used by Serbin et al. (2001) involving representations of the infants' own face as a test stimulus. Furthermore, care must be taken in the selection of gender-related attributes for infants and toddlers to ensure that they have had exposure to the gender-related attributes on which they are being tested. Without this exposure, infants would not be expected to acquire the stereotypic knowledge of the correlations.

Further research is needed to examine these hypothesized patterns of relations among emerging cognitions, affect, and behavior. The vast majority of the studies suggest that infants' and toddlers' level of gender knowledge is much higher than previously as- 
sumed. Thus, the new time line of gender development suggests that the original concern about cognitive mechanisms may have been premature and due to the limited methodology of the earlier studies. It appears that some early and rudimentary form of gender knowledge about self, about others, and about the behaviors associated with the sexes relates to children's own thinking and behavior. However, linking knowledge and behavior is methodologically challenging because of the limits of infants' and toddlers' ability to communicate their preferences and knowledge and because of the variability in children's exposure to gender stereotypic correlations in their social environments. Given the difficulty with interpreting findings involving familiar objects, it might be useful to examine preferences after familiarizing infants with gender category links to novel objects.

\section{Features of a Cognitive Approach to Gender Development}

The incorporation of cognitive perspectives in social learning theory, as represented by Bussey and Bandura's (1999) SCT, means that on many issues, cognitive and social learning approaches are now indistinguishable. For example, when a young child models the actions of several same-sex children but does not model other-sex children, the learning of and subsequent display of gender-typed behavior is viewed as consistent with cognitive theories as well as SCT. For both theories, the knowledge acquired from observational learning becomes part of a system of genderrelated beliefs and expectations that guide behavior. Cognitive theorists call this representational system a schema, whereas SCT refers to broader cognitive representational processes in observational learning without specifying the etiology and structure of such representations. At the same time, SCT is quite explicit about how representational processes influence behavior through selfregulation, whereas cognitive theories are somewhat more vague, referring to consistency and mastery motives. Despite the somewhat different emphases, modeling is essentially the same process with the same outcomes for the two theoretical approaches. The two theories are also in agreement that such gender-typed observational learning may begin early in life and that there are many reasons that the display of gender-typed behavior may be disconnected from gender cognitions (e.g., identity, constancy, stereotypic knowledge).

The basic processes believed important in stereotype development are largely similar in the two approaches. Children watch how both females and males behave, they attend to the associations between gender group members and their behavior, and they store basic information about the sexes. Social learning and socialcognitive theorists have played an important role in describing the conditions of modeling that increase the likelihood of children learning from models (e.g., Bussey \& Perry, 1976; Perry \& Bussey, 1979). Both cognitive and social-cognitive approaches consider modeling to be a key mechanism involved in learning stereotypes while recognizing that there are other routes for learning stereotypes, such as through social transmission of stereotypes by parents and peers.

Although not directly acknowledged in the latest version of SCT, basic gender identity (and its concomitant, presumed similarity) appears to be a facilitator of gender development in both theoretical approaches. Same-sex modeling and self-efficacy have no direction without gender identity in SCT; in cognitive theories, motivation and intergroup processes are largely dependent on the child having a sense of which sex they are.

Does the incorporation of cognitive perspectives in SCT imply that the theories are no longer different in important respects? In this section, we highlight the most significant features of cognitive theories that distinguish them from SCT - features that we believe suggest meaningful directions for future research.

\section{Evaluative and Motivational Consequences of Gender Identity}

A central tenet of cognitive approaches is that selfcategorization as a boy or girl has a number of immediate consequences for children's behaviors and orientation toward same-sex others. These include in-group favoritism (e.g., liking and preferential distribution of resources), motivation to be like same-sex others, and exaggeration of group differences. Hence, according to cognitive theorists, children who differ in their understanding of gender identity should also differ on various indices of gendertyped behavior, such as attention to same-sex models and preferences for same-sex peers, as described earlier.

In contrast, Bussey and Bandura (1999) questioned the idea, central to cognitive theories, that differential valuation follows same-sex identification. They stated that SCT does not invest such gender conceptions with "automatic directive and motivating properties":

Acquiring a conception of gender and valuing the attributes defining that conception are separable processes governed by different determinants ... we have demonstrated how self-regulatory mechanisms operate through perceived self-efficacy, anticipated social sanctions, self-sanctions, and perceived impediments rather than gender labeling itself motivating and guiding gender-linked conduct. (p. 696)

This position is curious given the extensive evidence derived from social identification theory (Tajfel, 1981) that "mere categorization" of individuals into different social groups is associated with greater liking for the in-group (relative to the out-group), perceived similarity to the in-group, and perceptions that the in-group is better than the out-group. A large body of literature shows that at least a mild form of in-group positivity biases arise automatically from identification with a social group (Brewer, 2001; Cameron, Alvarez, Ruble, \& Fuligni, 2001; Hewstone, Rubin, \& Willis, 2002; Ruble et al., in press). Young children of both sexes engage in such evaluations (e.g., Nesdale \& Flesser, 2001), and children show in-group gender biases as early as 3 years of age (Yee \& Brown, 1994). A number of variables may mitigate or enhance this in-group favoritism effect (Hewstone et al., 2002). For example, in an impressive series of studies with children, Bigler and her colleagues (Bigler, 1995; Bigler et al., 1997) have shown that children are most likely to form intergroup biases when membership in particular groups is perceptually salient or has functional value, such as being used by authority figures to label and organize the social environment. In addition, studies of stereotype development have shown quite definitively that young children view their own sex as having more positive characteristics than the other sex, yet another indication of in-group favoritism (Ruble \& Martin, 1998).

In short, the preponderance of evidence weighs in favor of group membership having important and pervasive effects on both chil- 
dren and adults. To argue otherwise requires not only substantial evidence in which such effects fail to be found but also explanations of why so many previous studies have found such patterns, especially using minimal groups. A heavy burden of proof is on Bussey and Bandura regarding the lack of motivational and evaluative consequences of self-categorization. Bussey and Bandura (1999) provided no evidence supporting their contention that selfcategorization as a boy or girl does not have such effects. Indeed, they suggested that once "self-categorization occurs, the label takes on added significance" (p. 696). Evidently, this added significance is not viewed as indicative of heightened motivation; then what exactly does it indicate?

Given this debate, a direct comparison of SCT and cognitive positions during the normal course of emerging gender categorization would be very productive. New methods may be needed to assess heightened motivation to learn about gender, as proposed by cognitive theorists. It would also be productive to compare the motivational accounts that are differentially emphasized across the different cognitive theories-for example, mastery (cognitivedevelopmental), consistency (schema), and self-evaluation (social identity). Moreover, it would be useful to examine how the different processes emphasized by SCT and cognitive theories may work together. For example, the mechanisms that Bussey and Bandura (1999) discussed in SCT need not replace group membership as motivators of behavior; instead, they may be viewed as additional and complementary motivators. Indeed, the motivational significance of social pressures to adhere to group norms as well as the importance of internalized beliefs about such pressures have been investigated by both cognitive and SCT approaches (Bussey \& Bandura, 1992; Egan \& Perry, 2001; Martin et al., 1999). It would be of considerable interest to know if the positive motivations associated with identification with a group and the negative forces of perceived pressure to comply with group norms or expectations work as additive or multiplicative processes in influencing gender-typed behavior. Recent research suggests that they may even operate in opposition for some outcomes at some ages (Egan \& Perry, 2001).

Furthermore, developmental changes in both the cognitive- and social-motivational processes underlying gender-typed behavior need to be further investigated. Rather than concentrating almost exclusively on gender labeling, researchers should direct more effort to different forms of gender understanding in infants, young children, and older children. Little attention has been paid to describing the changes and levels of complexity in conceptions of gender identity, which may serve as a motivator of behavior in older children, adolescents, and adults, although recent studies have begun to address this issue (Egan \& Perry, 2001; Hannover, 2000).

Similarly, the development of gender stereotypes and stereotyping processes needs further investigation. For instance, as children grow older, their cognitive ability to use multiple dimensions for classifying people allows them to develop more complex gender stereotypes consisting of subtypes of people, such as "girly girls" and "tomboys." These subtypes can then be used for classifying and evaluating people. Research on stereotyping processes, such as the automatic and controlled features of stereotyping (Devine, 1989), have received much more attention in the adult social psychological literature than in the developmental literature (Bennett, Sani, Hopkins, Agostini, \& Malucchi, 2000). This line of research is particularly interesting because it suggests that some adults are able to control the stereotyping process, thereby categorization need not always result in the differential treatment of stereotyped groups (Devine, 1989). However, this same research has clearly demonstrated that even controlled stereotype processing has subtle yet consistent effects on thinking. Developmental researchers should draw their attention toward a better integration of social psychological principles into children's research on stereotypes and gender concepts more generally, whereas social psychologists would benefit from further consideration about the origins and trajectories of stereotype development (Ruble \& Martin, in press).

\section{Active, Self-Initiated View of Gender Development}

The motivational properties of self-identification lead directly to another central element of cognitive views: Children actively seek out and construct their own rules about gender at an early age. This view contrasts with the role of the child implied in SCT (see Ruble \& Goodnow, 1998, for a more extended discussion of the theoretical distinction). Although SCT does portray children as active information processors, the emphasis on activity differs. Specifically, SCT does not view children as being intrinsically motivated to build on their gender schemas and construct personal standards of gender-appropriate conduct prior to the transition from external to internal regulation (which presumably marks the time when self-efficacy in gendered domains is gaining ascendancy). Children may be active information processors in SCT (they go beyond the observations at hand), but Bussey and Bandura (1999) are silent as to why children would want to-from the outsetmaster their knowledge about salient, meaningful, personally relevant, and value-laden categorical distinctions in their social environment.

Hypotheses from cognitive theories regarding active, constructive processes in young children have been supported, in part, by studies of children's information seeking. For example, as described earlier with regard to gender stereotype labeling, young children pay increased attention to, and show better memory for, information about how to carry out an activity when they believe it is more appropriate for their own sex than for the other sex (e.g., Bradbard et al., 1986). Similarly, once young children have a stable conception of gender categories, they selectively attend to same-sex models (Slaby \& Frey, 1975). These ideas about the active construction of knowledge conflict directly with SCT predictions that, for example, children learn about both male and female activities but then selectively display one or the other. Although Bussey and Bandura (1999) were not entirely consistent on this point, they appeared to support more strongly the position that children acquire a wide range of information during undirected observational and enactive learning. From this array of information, they piece together what is needed to enact a behavior. Evidence for these contrasting views is sparse. Further studies need to be conducted varying the depth of information that is to be learned, the time between presentation of the material and testing, and the degree to which different situations influence memory.

The presence of active construction is perhaps most evident when the process goes into overdrive or goes awry, resulting in faulty conclusions about gender roles and distorted perception and recall of gender-role-inconsistent information. Many experimental 
studies have demonstrated gender-based distortions in which children either misconstrue an activity or incorrectly remember the sex of the actor engaging in an activity to make their memories consistent with their gender cognitions (Carter \& Levy, 1988; Liben \& Signorella, 1980; Martin \& Halverson, 1983; Signorella \& Liben, 1984; Stangor \& Ruble, 1989). For instance, in a study involving videotaped presentations, children remembered female doctors as nurses (Cordua, McGraw, \& Drabman, 1979). Similarly, Martin and Halverson (1983) found that, after viewing pictures of people engaged in stereotype-consistent and stereotypeinconsistent activities, children were three times more likely to distort the sex of the actor in the inconsistent pictures than in the consistent ones. For example, children who were shown pictures of a girl sawing wood reported having seen a picture of a boy sawing wood (Martin \& Halverson, 1983). As described above, children also discount gender labels for novel toys supplied by an adult experimenter in favor of their own labels. In our own research, it has been difficult to generate stimuli that are perceived as neutral, because children appear to seize on any element that resembles a gender norm in order to categorize it as male or female.

Children's active role in gender development is evident in anecdotal reports describing how they often come up with idiosyncratic norms about gender. For example, Paley (1984) depicts preschool boys and girls as generating numerous ways to be different (e.g., boys hop to get their lunch boxes, whereas girls skip), whether or not these differences correspond in any way to prevalent gender stereotypes. Children are quick to notice sex differences and to draw conclusions about them, even when the differences are unrelated to sex. For example, Bjorklund (2000) reported an instance in which a 4-year-old eating at an Italian restaurant with four adults noticed that his father and another male ordered pizza whereas his mother ordered lasagna. On his way home in the car he announced that he had figured it out: "Men eat pizza and women don't" (Bjorklund, 2000, p. 361). Even a single representative of a distinction (e.g., that Mom drinks coffee and Dad drinks tea) may be sufficient for children to conclude that it is significant (e.g., that a male visitor who drinks coffee is violating a norm). Experimental research supports such observations that young children are quick to jump to conclusions about a newly observed difference between males and females. For example, preschoolers will infer that a novel property (e.g., "has little eggs inside") of a prototypic human figure also applies to a target figure of the same sex (Gelman et al., 1986). In another study with 3 -year-olds, Bauer and Coyne (1997) found that a single presentation of a neutral item paired with either a girl or a boy led to a categorical inference. For example, if they were told that a boy likes a sofa and a girl likes a table, children would infer that another girl would like the table.

Such "errors" in children's emerging conclusions about gender norms are reminiscent of findings in the language acquisition literature. Language diaries and tapes show that young children's grammatical errors often indicate overgeneralization of a rule, such as adding - $e d$ for the past tense of all verbs-for example, "I eated that yesterday"; "He goed to the store." These errors seem to reflect in part the active, constructive processes in acquiring and applying rules (G. F. Marcus et al., 1992). Moreover, like the spurt in vocabulary acquisition that occurs during children's second year (Tamis-LeMonda, Bornstein, Kahana-Kalman, Baumwell, \& Cyphers, 1998), the remarkable rate at which children appear to acquire gender stereotypes after age 3 is much faster than would seem possible if it were dependent on direct instruction from socializing agents or even observations of multiple instances, as allowed by SCT. Active inferential processes based on minimal information would seem to be a likely mechanism (Bauer \& Coyne, 1997). Future research modeled on the language acquisition work, perhaps using parental diaries or selective audiotaping, may help elucidate the frequency and significance of such attempts by young children to construct theories of gender.

In short, SCT and cognitive theories differ in how actively the child is seen in constructing gender, and this difference rests largely on the theories having disparate views of the motivational processes associated with gender norms. From a cognitive perspective, such motivation involves deliberate efforts to learn about a newly developing social category; it has to do with the initial composition of category knowledge and, more generally, with the active construction of meaning about the social world and one's place in it. From a social-cognitive perspective, the motivation, self-efficacy, is equated with developing competence in a particular area of functioning; it has to do with the effective enactment of developing skills. What is missing from this perspective is an account of how children take an active role not only in developing their skills in emitting gender-typed behaviors but also in developing their knowledge base of gender to guide their behaviors and attitudes. Self-efficacy alone does not inform children about which gender domains are "appropriate" for them. It does not provide direction to children's desire to succeed in a specific area of functioning.

\section{Developmental Pattern}

A third key element of cognitive theories is an emphasis on developmental features of gender typing. The literature suggests that the relative strength or rigidity of gender-related knowledge and behavior waxes and wanes across development. For example, research shows that gender stereotyping about the kinds of objects and activities associated with males and females emerges between 2 and 4 years of age, reaches a peak of rigidity between 5 and 7 years, shows greater flexibility during middle childhood (Serbin et al., 1993; Signorella et al., 1993; Trautner, 1992), but may intensify once again during adolescence (Ruble \& Martin, 1998). This pattern of a peak of rigidity between 5 and 7 years followed by greater flexibility is consistent with cognitivedevelopmental hypotheses (Kohlberg, 1966) that children should be highly motivated to learn about and master their gender role at about the time that they have acquired gender constancy, between 5 and 7 years of age. Related formulations have argued that once a categorical distinction such as gender is recognized as important, there may be phaselike shifts in the rigidity of categoryrelevant beliefs and behaviors, moving from a beginning awareness, to rigidity, to flexibility (e.g., Trautner, 1992). According to these perspectives, a relatively rigid phase of "consolidation" (Ruble, 1994) or "schema confirmation" (Welch-Ross \& Schmidt, 1996) is predicted to follow a phase of learning about gender (construction/information gathering) and to precede a phase of relative flexibility (integration and schema deployment).

Considerable evidence supports the consolidation phase of this process, showing that young children actively reconstruct information to be consistent with their growing conceptions of what 
males and females can and cannot do (e.g., Cordua et al., 1979; Signorella \& Liben, 1984; Stangor \& Ruble, 1989). Gender schema perspectives propose a similar process. Children's recognition of their membership in a gender category motivates them to learn details and scripts for activities stereotypically associated with their own sex and to act in accordance with them. Subsequently, the impact of the schema will lessen with the emergence of other cognitive-developmental processes, such as flexibility in classification, and with individual differences in values, gender salience, and schema elaboration.

The literature on children's gender-related preferences and behaviors has shown somewhat more mixed developmental trends (Ruble \& Martin, 1998). Some studies of children's verbal preferences for gender-typed activities (e.g., sawing, hammering, fighting, feeding baby, ironing, and cooking) suggest that the strength of gender-typed preferences increases until age 7 years or so and then levels off (e.g., Trautner, 1992); others find fairly stable gender-typed preferences from age 5 on (e.g., Serbin et al., 1993); still others find a decline in gender-typed preferences in the middle grades of school for girls but not for boys (e.g., Katz \& Boswell, 1986). Children's preferences in these studies do not seem to be characterized as extremely rigid, nor as reaching a peak that then declines. In contrast, school-based observations of behavior suggest extensive rigidity of behavior in 3-6-year-olds (Lloyd \& Duveen, 1992; Paley, 1984; Richner \& Nicolopoulou, 2001). Maccoby (1988) described the clear divergence in children's pretend play during preschool, with boys enacting heroic characters and themes of danger and righteous combat and girls enacting cooperative role-taking (teacher-student) and themes of glamour and romance. In addition, parents describe preschool girls as being very insistent on looking feminine (e.g., wearing pink, frilly dresses), but this form of gender-typed rigidity generally appears to decline after a few years (Greulich, Ruble, Khuri, Cyphers, \& Szkrybalo, 2002). In short, the curvilinear patterns shown for preferences and behaviors may depend on the measure, with certain kinds of gender displays being extremely pronounced during preschool or shortly thereafter. Support for a cognitive influence on these indices of gender typing comes from the studies described earlier, showing links between various stages of genderrelated cognitions (i.e., stereotype knowledge and identity, including constancy) and gender-related preferences and behaviors. Developmental changes may also be linked to changes in the nature of socialization influences, such as children entering school and spending more time with peers. For instance, only a few months of exposure to same-sex peers tends to encourage more gender-typed play in children (Eisenberg, Tryon, \& Cameron, 1984; Martin \& Fabes, 2001; Shell \& Eisenberg, 1990).

SCT also refers to developmental processes in the sense of a sequence of events, such as self-regulation occurring relatively late in gender development. Nevertheless, the curvilinear patterns observed in the literature would seem difficult for this theory to explain unless socialization processes also wax and wane. It is possible, of course, that the exaggerated gender typing occurring in young children is partly due to the influence of same-sex peers because sex segregation increases during this time. Why these behaviors would decline, though, in the face of increasing sex segregation is unclear.

\section{Moving Toward Integration}

Cognitive theories were not the only perspectives dismissed by Bussey and Bandura (1999), and we believe that progress in the field depends on links with these other views. For instance, biological views need to be incorporated into integrative perspectives. Important biologically oriented studies have been done with children with hormone disorders suggesting that prenatal hormones influence these girls' behavior (Berenbaum \& Hines, 1992; Berenbaum \& Snyder, 1995). Furthermore, the interaction of biological and social factors needs further exploration. For example, a recent biological study attempted to address the important issue of whether vulnerability to socialization experiences relates to prenatal hormone exposure. Udry (2000) found that women who had been exposed to higher levels of androgens prenatally were less open to socialization into feminine roles than were other women. Much more effort needs to be directed into identifying how biological and early hormone environments work in interaction with cognitive and social factors to influence development. Furthermore, within the last 10 years, interest in biological, cognitive, and social factors has been invigorated by research done on children and adults who either have a mismatch between their genetic and/or hormonal patterns and their gender of rearing or are born with ambiguous genitalia. In addition to the medical management issues surrounding these individuals, the psychological issues about gender identity development, how to best raise these children, and their likely outcomes have brought issues about gender identity, behavior, and expectations to the forefront of psychological research (Bradley, Oliver, Chernick, \& Zucker, 1998; Diamond \& Sigmundson, 1997; Money \& Ehrhardt, 1972). Collaborative efforts with biologically oriented theorists could address such important issues as whether there is a critical or sensitive period for gender identity and the roles of social, biological, and cognitive factors on the development of gender identity.

Another recent and influential perspective on gender-linked behavior is Maccoby's $(1988,2002)$ analyses of the role of group processes in gender development. According to this perspective, the high level of sex segregation beginning in the preschool years means that gender is enacted in childhood largely in the context of same-sex groups. In this sense, then, sex segregation might represent a more important antecedent to sex-typed behavior than other influences, such as the family. Moreover, according to this view, gender-linked qualities occur at the level of the group, as the group evolves, rather than at the level of the individual. Thus, although this perspective shares certain features with SCT, in the emphasis on contextual factors, it differs with its heavy emphasis on peers and de-emphasis on individual-based gender-typed behavior.

Finally, a comprehensive perspective requires additional links with feminist perspectives on power and structure and with the views that gender is socially constructed in moment-to-moment interactions (Deaux \& LaFrance, 1998). Cross-cultural studies and studies of variations within culture allow for comparisons of potential differences in power and structure. Children's sex differences in access to various play opportunities, adolescents' access to team sports and to academic courses, and encouragement for different careers are all forms of discrimination that can perpetuate gender inequalities. These are interesting topics to be investigated within the area of gender studies (Leaper, 2000). Research in the social psychological literature on the distribution of men and 
women into social roles has provided important insights into the development of gender stereotypes (see Eagly, Wood, \& Diekman, 2000). Additionally, comprehensive perspectives need to consider variation in assessments and variability across individuals in gender development. What are the developmental consequences of engaging in cross-sex play or having other-sex playmates? How does the enactment of gender vary across situations? Children and adults create gendered experiences in their everyday interactions, yet little is known about these complexities of gender development. Dynamic systems perspectives (Thelen \& Smith, 1998) may provide useful methods for considering the fluidity of gendered judgments in everyday interactions and in common social behaviors (Martin, 2000; Ruble \& Martin, 1998).

As Maccoby (2002) argues, however, promising directions for future research involve the integration of the individual and group perspectives. Such an integration would involve both normative developmental and individual difference aspects of gender development and would thus involve processes from both cognitive and social learning perspectives. For example, recent research has suggested not only that young children's (4-6 years old) stereotypic cognitions about gender are more rigid than older children's but also that they are more likely to be influenced by the presence of peers to portray themselves as having more stereotyped personal preferences (Banarjee \& Lintern, 2000). Moreover, as Maccoby notes and recent research (Martin \& Fabes, 2001) has shown in terms of individual differences, children who, for whatever reason, spend time in same-sex groups show greater gender typing. It also seems possible that the influence is reciprocal - that is, that children who exhibit more gender-typed characteristics are more likely to be accepted by the group. It will be interesting in future research to examine what characteristics of children lead them to be accepted or rejected by same-sex groups or to self-select into such groups.

In terms of normative development, gender typing and sex segregation show similar characteristics, at least among young children. They emerge at about the same time and seemingly with about the same degree of intensity. One might even speculate that sex segregation and gender typing emerge as part of the same set of mechanisms, such as those connected with social identification. A friend of ours told the story about her grandson's first day at preschool. She asked him what he had learned. He said he learned something very important - that there was a boys' group and a girls' group, and that he got to be part of the boys' group! During that year, he became quite "macho." As described earlier, according to social identity theory and findings such as those of Bigler et al. (1997), self-categorization as a boy or a girl has a number of immediate consequences for children's orientations toward samesex others and behaviors. These include both in-group favoritism, which would lead to sex segregation, and motivation to be like same-sex others and exaggeration of group differences, which would lead to gender-typed behavior. Thus, gender typing and sex segregation are likely both directed, at some level, by a child's own sense of self and place in the gender world. Future research should jointly examine the roles of gender identification and peer socialization processes on gender typing and its possible association with sex segregation.

\section{Conclusion}

The main goals of this article have been to refute recent critiques of the role of cognitive theories in understanding gender development and to evaluate the contribution of cognitive perspectives to a contemporary understanding of gender development. This review represents, in part, a continuation of a debate between social learning and cognitive accounts of gender development begun in the chapters of Maccoby's (1966) groundbreaking volume on the psychology of sex differences. Since then, each perspective has evolved and incorporated elements of the other. During this period, the two differing views have peacefully coexisted, along with other theories, recognizing that multiple perspectives are necessary to fully account for the scope and complexity of gender development.

The present article was prompted in part by the reopening of the debate by Bussey and Bandura (1999). As part of their presentation of an SCT of gender development, they argued that there is no evidence for alternative theories, neither cognitive nor biological, and that such theories are no longer needed anyway because SCT provides a comprehensive account of gender development. We disagree on three primary grounds: (a) There is considerable direct empirical support for cognitive accounts of gender development; (b) SCT is far from comprehensive; and (c) joint considerations of multiple perspectives raises interesting and important questions about gender development that would not be considered by the SCT view alone.

First, as we have shown, the evidence demonstrating a relation between gender cognitions and behavior is stronger than Bussey and Bandura (1999) implied. As reviewed in previous sections, support for cognitive views includes (a) links between level of identification with gender (identity, labeling, stability, constancy) and several different aspects of gender-typed behavior; (b) links between knowledge of gender stereotypes and behavior, especially in experimental and correlational studies that have avoided certain pitfalls; and (c) research indicating that both gender identification and knowledge may be found in primitive forms in infancy, prior to the emergence of many gender-typed behaviors. Furthermore, beyond the evidence of links between gender cognitions and behavior, many empirical studies have confirmed the role of gender-related cognitive structures and processes in memory, attention, impression formation, and inductive reasoning. Moreover, we have argued that the processes emphasized in SCT would not operate logically without resorting to the very cognitive processes they have discounted. In contrast to the strong empirical evidence in support of cognitive theories, there is little direct evidence supporting several key notions of SCT. Thus, despite Bussey and Bandura's contention, cognitive-developmental elements are necessary components of any comprehensive account of gender development, and their proposals suggesting that they have replaced these mechanisms with more comprehensive mechanisms are unproven.

Second, even with its consideration of the role of cognition in gender development, SCT has not simply subsumed all that is encompassed within cognitive theories. Cognitive theories draw on a rich theoretical history and have linkages with social-cognitive perspectives of behavior, as well as with research on language development and conceptual development. Cognitive theories of gender also incorporate pervasive assumptions about developmental processes, including the highly active role of the child in 
development, the importance of motivation to attain mastery and to develop a sense of belongingness, and a strong emphasis on developmental change. Furthermore, cognitive theories call attention to a number of other significant gender-related processes, as well as offer a variety of alternative methodologies. These include (a) the emerging sense of identification with a group, its implications for learning as well as for adjustment and belonging (e.g., Egan \& Perry, 2001), and the relative significance of gender in one's hierarchy of self-concept (e.g., Ashmore, Del Boca, \& Bilder, 1995); (b) learning and applying stereotypes about groups, with their implications for discrimination and exclusion (e.g., Stangor \& Lange, 1994); and (c) the normative course of genderrelated phenomena, linked to basic developmental change, such as cognitive accomplishments (e.g., ability to categorize) and social life phases (e.g., adolescence).

Third, there is widespread agreement in the field that a complete understanding of gender development requires an integration of many different perspectives. Social learning theory in its current incarnation as SCT has done some of that by its incorporation of cognitive perspectives. But by dismissing alternative theories and replacing them with one purportedly comprehensive theory, Bussey and Bandura (1999) may have taken the field a step backward rather than forward. In arguing that cognitive theories are no longer relevant, they have a difficult time explaining certain key SCT processes, such as the motivation for same-sex modeling. In our view, the contribution of SCT would be much greater if it were to embrace alternative accounts and work with them in a multidisciplinary fashion to identify and examine interesting and important questions. Ideas from both the social-cognitive and cognitive perspectives have a place in developing integrative views of gender development.

In short, it is not so much that SCT is necessarily wrong about certain aspects of gender development but that it is incomplete. Theories that they ignore or dismiss are needed for a comprehensive understanding of gender development. Cognitive approaches have made many important contributions to the understanding of gender development. The cognitive emphasis suggests that children are actively involved in learning about gender and will make creative conceptual constructions of what they believe to be true. Because of the focus on how children construct a gendered world, much of the cognitive-oriented research has involved assessing various knowledge structures including gender stereotypes and understanding of gender categories. Cognitive perspectives have been central for highlighting the value of understudied domains of gender development including how children apply stereotypes in their decision making and impression formation, the development of stereotypes, the development of gender identity, how children process and remember gendered information, what they pay attention to, and how these processes relate to children's behavior. All in all, the cognitive emphasis in the study of gender development has opened vast new vistas of study-impression formation, memory, attention, and inductive reasoning, to name just a few. This unique and rich perspective will continue to have much to offer researchers as they strive for comprehensive, cohesive, and inclusive theories of gender development.

\section{References}

Asendorph, J. B., Warkentin, V., \& Baudonniere, P. M. (1996). Selfawareness and other-awareness: II. Mirror self-recognition, social con- tingency awareness, and synchronic imitation. Developmental Psychology, 32, 313-321.

Ashmore, R. D., \& Del Boca, F. (1979). Sex stereotypes and implicit personality theory: Toward a cognitive-social psychological conceptualization. Sex Roles, 5, 219-248.

Ashmore, R. D., \& Del Boca, F. K. (1981). Conceptual approaches to stereotypes and stereotyping. In D. L. Hamilton (Ed.), Cognitive processes in stereotyping and intergroup behavior (pp. 1-35). Hillsdale, NJ: Erlbaum.

Ashmore, R. D., Del Boca, F. K., \& Bilder, S. M. (1995). Construction and validation of the Gender Attitude Inventory, a structured inventory to assess multiple dimensions of gender attitudes. Sex Roles, 32, 753-785.

Aubry, S., Ruble, D. N., \& Silverman, L. B. (1999). The role of gender knowledge in children's gender-typed preferences. In L. Balter \& C. S Tamis-LeMonda (Eds.), Child psychology: A handbook of contemporary issues (pp. 363-390). New York: Psychology Press.

Baldwin, D. A., \& Moses, L. K. (1996). The ontogeny of social information gathering. Child Development, 67, 1915-1939.

Banarjee, R., \& Lintern, V. (2000). Boys will be boys: The effect of social evaluation concerns on gender-typing. Social Development, 9, 397-408.

Bandura, A. (1977). Social learning theory. Englewood Cliffs, NJ: Prentice Hall.

Bandura, A. (1986). Social foundations of thought and action: A social cognitive theory. Englewood Cliffs, NJ: Prentice Hall.

Bandura, A. (1991a). Self-regulation of motivation through anticipatory and self-regulatory mechanisms. In R. A. Dienstbier (Ed.), Nebraska Symposium on Motivation: Perspectives on motivation (Vol. 38, pp. 69-164). Lincoln: University of Nebraska Press.

Bandura, A. (1991b). Social cognitive theory of moral thought and action. In W. M. Kurtines \& J. L. Gewirtz (Eds.), Handbook of moral behavior and development (Vol. 1, pp. 45-103). Hillsdale, NJ: Erlbaum.

Bandura, A. (1992). Social cognitive theory of social referencing. In S. Feinman (Ed.), Social referencing and the social construction of reality in infancy (pp. 175-208). New York: Plenum.

Barkley, R. A., Ullman, D. G., Otto, L., \& Brecht, J. M. (1977). The effects of sex typing and sex appropriateness of modeled behavior on children's imitation. Child Development, 48, 721-724.

Bauer, P. J. (1993). Memory for gender-consistent and gender-inconsistent event sequences by twenty-five-month-old children. Child Development, 64, 285-297.

Bauer, P. J., \& Coyne, M. J. (1997). When the name says it all: Preschoolers' recognition and use of the gendered nature of common proper names. Social Development, 6, 271-291.

Bem, S. L. (1981). Gender schema theory: A cognitive account of sex typing. Psychological Review, 88, 354-364.

Bem, S. L. (1989). Genital knowledge and gender constancy in preschool children. Child Development, 60, 649-662.

Bennett, M., Sani, F., Hopkins, N., Agostini, L., \& Malucchi, L. (2000). Children's gender categorization: An investigation of automatic processing. British Journal of Developmental Psychology, 18, 97-102.

Berenbaum, S. A., \& Hines, M. (1992). Early androgens are related to childhood sex-typed toy preferences. Psychological Science, 3, 203206

Berenbaum, S. A., \& Snyder, E. (1995). Early hormonal influences on childhood sex-typed activity and playmate preferences: Implications for the development of sexual orientation. Developmental Psychology, 31, $31-42$.

Berndt, T., \& Heller, K. A. (1986). Gender stereotypes and social inferences: A developmental study. Journal of Personality and Social Psychology, 50, 889-898.

Bigler, R. S. (1995). The role of classification skill in moderating environmental effects on children's gender stereotyping: A study of the 
functional use of gender in the classroom. Child Development, 66, 1072-1087.

Bigler, R. S., Jones, L. C., \& Lobliner, D. B. (1997). Social categorization and the formation of intergroup attitudes in children. Child Development, 68, 530-543.

Bjorklund, D. F. (2000). Children's thinking: Developmental function and individual differences (3rd ed.). Belmont, CA: Wadsworth.

Blakemore, J. E., LaRue, A. A., \& Olejnik, A. B. (1979). Sex-appropriate toy preference and the ability to conceptualize toys as sex-role related. Developmental Psychology, 15, 339-340.

Boston, M. B., \& Levy, G. D. (1991). Changes and differences in preschoolers' understanding of gender scripts. Cognitive Development, 6 , 412-417.

Bradbard, M. R., \& Endsley, R. C. (1983). The effects of sex-typed labeling on preschool children's information-seeking and retention. Sex Roles, 9, 247-260.

Bradbard, M. R., Martin, C. L., Endsley, R. C., \& Halverson, C. F. (1986). Influence of sex stereotypes on children's exploration and memory: A competence versus performance distinction. Developmental Psychology, 22, 481-486.

Bradley, S. J., Oliver, G. D., Chernick, A. B., \& Zucker, K. J. (1998). Experiment of nurture: Ablatio penis at 2 months, sex reassignment at 7 months, and a psychosexual follow-up in young adulthood. Pediatrics, 102, 1-5.

Brewer, M. B. (2001). Ingroup identification and intergroup conflict: When does ingroup love become outgroup hate? In R. D. Ashmore, L. Jussim, \& D. Wilder (Eds.), Social identity, intergroup conflict, and conflict reduction (pp. 17-41). New York: Oxford University Press.

Bussey, K. (1983). A social-cognitive appraisal of sex-role development. Australian Journal of Psychology, 35, 135-143.

Bussey, K., \& Bandura, A. (1984). Influence of gender constancy and social power on sex-linked modeling. Journal of Personality and Social Psychology, 47, 1292-1302.

Bussey, K., \& Bandura, A. (1992). Self-regulatory mechanisms governing gender development. Child Development, 63, 1236-1250.

Bussey, K., \& Bandura, A. (1999). Social-cognitive theory of gender development and differentiation. Psychological Review, 106, 676-713.

Bussey, K., \& Perry, D. G. (1976). Sharing reinforcement contingencies with a model: A social-learning analysis of similarity effects in imitation research. Journal of Personality and Social Psychology, 34, $1168-1176$

Bussey, K., \& Perry, D. G. (1982). Same-sex imitation: The avoidance of cross-sex models or the acceptance of same-sex models? Sex Roles, 8 , 773-784.

Caldera, Y. M., Huston, A. C., \& O’Brien, M. (1989). Social interactions and play patterns of parents and toddlers with feminine, masculine, and neutral toys. Child Development, 60, 70-76.

Cameron, J. A., Alvarez, J. M., Ruble, D. N., \& Fuligni, A. J. (2001). Children's lay theories about ingroups and outgroups: Reconceptualizing research on "prejudice." Personality and Social Psychology Review, 5, 118-128.

Campbell, A., Shirley, L., \& Heywood, C. (2000). Infants' visual preference for sex-congruent babies, children, toys and activities: A longitudinal study. British Journal of Developmental Psychology, 18, 479-498.

Cann, A., \& Palmer, S. (1986). Children's assumptions about the generalizability of sex-typed abilities. Sex Roles, 15, 551-558.

Carter, D. B., \& Levy, G. D. (1988). Cognitive aspects of children's early sex-role development: The influence of gender schemas on preschoolers' memories and preferences for sex-typed toys and activities. Child Development, 59, 782-793.

Coker, D. R. (1984). The relationships among gender concepts and cognitive maturity in preschool children. Sex Roles, 10, 19-31.

Constantinople, A. (1979). Sex-role acquisition: In search of the elephant. Sex Roles, 5, 121-132.
Cordua, G. D., McGraw, K. O., \& Drabman, R. S. (1979). Doctor or nurse: Children's perception of sex typed occupations. Child Development, 50, 590-593.

Corneille, O., \& Judd, C. M. (1999). Accentuation and sensitization effects in the categorization of multifaceted stimuli. Journal of Personality and Social Psychology, 77, 927-941.

Cornell, E. H. (1974). Infants' discrimination of photographs of faces following redundant presentations. Journal of Experimental Psychology, 18, 98-106.

Courage, M. L., \& Howe, M. L. (2002). From infant to child: The dynamics of cognitive change in the second year of life. Psychological Bulletin, 128, 250-277.

Cowan, G., \& Hoffman, C. D. (1986). Gender stereotyping in young children: Evidence to support a concept-learning approach. Sex Roles, 14, 211-224.

Dasgupta, N., Banaji, M. R., \& Abelson, R. P. (1999). Group entitativity and group perception: Associations between physical features and psychological judgment. Journal of Personality and Social Psychology, 77, 991-1003.

Davies, D. R. (1986). Children's performance as a function of sex-typed labels. British Journal of Social Psychology, 25, 173-175.

Davies, D. R. (1989). The effects of gender-typed labels on children's performance. Current Psychology: Research \& Reviews, 8, 267-272.

Deaux, K., \& La France, M. (1998). Gender. In D. Gilbert, S. Fiske, \& G. Lindzey (Eds.), Handbook of social psychology (pp. 788-827). Boston: McGraw-Hill.

De Lisi, R., \& Johns, M. L. (1984). The effects of books and gender constancy development on kindergarten children's sex-role attitudes. Journal of Applied Developmental Psychology, 5, 173-184.

Devine, P. G. (1989). Stereotypes and prejudice: Their automatic and controlled components. Journal of Personality and Social Psychology, 56, 5-18.

Diamond, M., \& Sigmundson, H. K. (1997). Sex reassignment at birth: Long-term review and clinical implications. Archives of Pediatric Adolescent Medicine, 151, 298-304.

Eagly, A. H., Wood, W., \& Diekman, A. B. (2000). Social role theory of sex differences and similarities: A current appraisal. In T. Eckes \& H. Trautner (Eds.), The developmental social psychology of gender (pp. 123-174). Mahwah, NJ: Erlbaum.

Eaton, W. O., \& Enns, L. R. (1986). Sex differences in human motor activity level. Psychological Bulletin, 100, 19-28.

Edelbrock, C., \& Sugawara, A. I. (1978). Acquisition of sex-typed preferences in preschool children. Developmental Psychology, 14, $614-623$.

Egan, S. K., \& Perry, D. G. (2001). Gender identity: A multidimensional analysis with implications for psychosocial adjustment. Developmental Psychology, 37, 451-463.

Eichstedt, J. A., Serbin, L. A., Poulin-Dubois, D., \& Sen, M. G. (in press). Of bears and men: Infants' knowledge of conventional and metaphorical gender stereotypes. Infant Behavior and Development.

Eisenberg, N., Tryon, K., \& Cameron, E. (1984). The relation of preschoolers' peer interaction to their sex-typed toy choices. Child Development, 55, 1044-1050.

Emmerich, W. (1982). Nonmonotonic developmental trends in social cognition: The case of gender identity. In S. Strauss (Ed.), U-shaped behavioral growth (pp. 249-269). New York: Academic Press.

Emmerich, W., Goldman, K. S., Kirsh, B., \& Sharabany, R. (1977). Evidence for a transitional phase in the development of gender constancy. Child Development, 48, 930-936.

Etaugh, C., Collins, G., \& Gerson, A. (1975). Reinforcement of sex-typed behaviors of two-year-old children in a nursery school setting. Developmental Psychology, 11, 255.

Etaugh, C., Grinnell, K., \& Etaugh, A. (1989). Development of gender labeling: Effect of age of pictured children. Sex Roles, 21, 769-773. 
Fagot, B. I. (1974). Sex differences in toddlers' behavior and parental reaction. Developmental Psychology, 10, 554-558.

Fagot, B. I. (1985). Changes in thinking about early sex role development. Developmental Review, 5, 83-98.

Fagot, B. I., \& Leinbach, M. D. (1985). Gender identity: Some thoughts on an old concept. Journal of the American Academy of Child Psychiatry, 24, 684-688.

Fagot, B. I., \& Leinbach, M. D. (1989). The young child's gender schema: Environmental input, internal organization. Child Development, 60, 663-672.

Fagot, B. I., Leinbach, M. D., \& Hagan, R. (1986). Gender labeling and the adoption of sex-typed behaviors. Developmental Psychology, 22, 440443

Fein, G., Johnson, D., Kosson, N., Stork, L., \& Wasserman, L. (1975). Sex stereotypes and preferences in the toy choices of 20-month-old boys and girls. Developmental Psychology, 11, 527-528.

Fiser, J., \& Aslin, R. N. (2001). Unsupervised statistical learning of higher-order spatial structures from visual scenes. Psychological Science, 12, 499-504.

Ford, T. E., \& Stangor, C. (1992). The role of diagnosticity in stereotype formation: Perceiving group means and variances. Journal of Personality and Social Psychology, 63, 356-367.

Frey, K. S., \& Ruble, D. N. (1992). Gender constancy and the "cost" of sex-typed behavior: A test of the conflict hypothesis. Developmental Psychology, 28, 714-721.

Gelman, S. A. (1989). Children's use of categories to guide biological inferences. Human Development, 32, 65-71.

Gelman, S. A., Collman, P., \& Maccoby, E. E. (1986). Inferring properties from categories versus inferring categories from properties: The case of gender. Child Development, 57, 396-404.

Gelman, S. A., \& Markman, E. M. (1987). Young children's inductions from natural kinds: The role of categories and appearances. Child Development, 58, 1532-1541.

Gold, D., \& Berger, C. (1978). Problem-solving performance of young boys and girls as a function of task appropriateness and sex identity. Sex Roles, 4, 183-193.

Greulich, F. F. K., Ruble, D. N., Khuri, J., Cyphers, L., \& Szkrybalo, J. (2002). Parents' report of children's gender-typed beliefs and behaviors: Cross-sectional and longitudinal analyses of children and adolescents. Manuscript submitted for publication.

Haith, M. M., \& Benson, J. B. (1998). Infant cognition. In D. Kuhn \& R. S. Siegler (Eds.), Handbook of child psychology (Vol. 2, pp. 199-254). New York: Wiley.

Hannover, B. (2000). Development of the self in gendered contexts. In T. Eckes \& H. M. Trautner (Eds.), The developmental social psychology of gender (pp. 177-206). Mahwah, NJ: Erlbaum.

Hargreaves, D. J., Bates, H. M., \& Foot, J. M. (1985). Sex-typed labelling affects task performance. British Journal of Social Psychology, 24, 153-155.

Haugh, S. S., Hoffman, C. D., \& Cowan, G. (1980). The eye of the very young beholder: Sex typing of infants by young children. Child Development, 51, 598-600.

Herzog, E. W., Enright, M., Luria, Z., \& Rubin, J. Z. (1982). Do gender labels yield sex differences in preferences, or is label a fable? Developmental Psychology, 18, 424-430.

Hewstone, M., Rubin, M., \& Willis, H. (2002). Intergroup bias. Annual Review of Psychology, 53, 575-604.

Hornik, R., \& Gunnar, M. R. (1988). A descriptive analysis of social referencing. Child Development, 59, 626-634.

Huston, A. C. (1983). Sex typing. In E. M. Hetherington (Ed.), Handbook of child psychology: Socialization, personality, and social development (4th ed., Vol. 4, pp. 387-467). New York: Wiley.

Huston, A. C. (1985). The development of sex-typing: Themes from recent research. Developmental Review, 5, 1-17.
Katz, P. A., \& Boswell, S. (1986). Flexibility and traditionality in children's gender roles. Genetic, Social, and General Psychology Monographs, 112, 103-147.

Katz, P. A., \& Kofkin, J. A. (1997). Race, gender, and young children. In S. S. Luthar, J. A. Burack, D. Cicchetti, \& J. R. Weisz (Eds.), Developmental psychopathology: Perspectives on adjustment, risk, and disorder (pp. 51-74). New York: Cambridge University Press.

Keil, F. C. (1991). The emergence of theoretical beliefs as constraints on concepts. In S. Carey \& R. Gelman (Eds.), The epigenesis of mind (pp. 237-256). Hillsdale, NJ: Erlbaum.

Kohlberg, L. A. (1966). A cognitive-developmental analysis of children's sex role concepts and attitudes. In E. E. Maccoby (Ed.), The development of sex differences (pp. 82-173). Stanford, CA: Stanford University Press.

Leaper, C. (2000). The social construction and socialization of gender during development. In P. H. Miller \& E. K. Scholnick (Eds.), Toward a feminist developmental psychology (pp. 127-152). New York: Taylor \& Francis/Routledge.

Leinbach, M. D., \& Fagot, B. I. (1986). Acquisition of gender labels: A test for toddlers. Sex Roles, 15, 655-666.

Leinbach, M. D., \& Fagot, B. I. (1993). Categorical habituation to male and female faces: Gender schematic processing in infancy. Infant Behavior and Development, 16, 317-332.

Leinbach, M. D., Hort, B. E., \& Fagot, B. I. (1997). Bears are for boys: Metaphorical associations in young children's gender stereotypes. Cognitive Development, 12, 107-130.

Levy, G. D. (1999). Gender-typed and non-gender-typed category awareness in toddlers. Sex Roles, 41, 851-873.

Levy, G. D., \& Carter, D. B. (1989). Gender schema, gender constancy, and gender-role knowledge: The roles of cognitive factors in preschoolers' gender-role stereotype attributions. Developmental Psychology, 25, $444-449$.

Levy, G. D., \& Haaf, R. A. (1994). Detection of gender-related categories by 10-month-old infants. Infant Behavior and Development, 17, 457459.

Lewis, M., \& Brooks-Gunn, J. (1979). Social cognition and the acquisition of self. New York: Plenum Press.

Liben, S. L., \& Bigler, R. S. (in press). The developmental course of gender differentiation: Conceptualizing, measuring, and evaluating constructs and pathways. Monographs of the Society for Research in Child Development.

Liben, L. S., \& Signorella, M. L. (1980). Gender-related schemata and constructive memory in children. Child Development, 51, 11-18.

Lloyd, B., \& Duveen, G. (1992). Gender identities and education. New York: St. Martin's Press.

Lobel, T. E., Bar-David, E., Gruber, R., Lau, S., \& Bar-Tal, Y. (2000). Gender schema and social judgments: A developmental study of children from Hong Kong. Sex Roles, 43, 19-42.

Lobel, T. E., \& Menashri, J. (1993). The relations of conceptions of gender-role transgressions and gender constancy to gender-typed toy preferences. Developmental Psychology, 29, 150-155.

Luecke-Aleksa, D., Anderson, D. R., Collins, P. A., \& Schmitt, K. L. (1995). Gender constancy and television viewing. Developmental Psychology, 31, 773-780.

Maccoby, E. E. (Ed.). (1966). The development of sex differences. Stanford, CA: Stanford University Press.

Maccoby, E. E. (1988). Gender as a social category. Developmental Psychology, 24, 755-765.

Maccoby, E. E. (1990). The role of gender identity and gender constancy in sex-differentiated development. New Directions for Child Development, 47, 5-20.

Maccoby, E. E. (2002). Gender and group process: A developmental perspective. Current Directions in Psychological Science, 11, 54-58. 
Maccoby, E. E., \& Jacklin, C. N. (Eds.). (1974). The psychology of sex differences. Stanford, CA: Stanford University Press.

Mandler, J. M., \& McDonough, L. (1996). Drinking and driving don't mix: Inductive generalization in infancy. Cognition, 59, 307-355.

Marcus, D. E., \& Overton, W. F. (1978). The development of cognitive gender constancy and sex role preferences. Child Development, 49, 434-444.

Marcus, G. F., Pinker, S., Ullman, M., Hollander, M., Rosen, T. J., \& Wu, F. (1992). Overregularization in language acquisition. Monographs of the Society for Research in Child Development, 57(4, Serial No. 228).

Marcus, H., Crane, M., Bernstein, S., \& Siladi, M. (1982). Self-schemas and gender. Journal of Personality and Social Psychology, 42, 38-50.

Martin, C. L. (1989). Children's use of gender-related information in making social judgments. Developmental Psychology, 25, 80-88.

Martin, C. L. (1991). The role of cognition in understanding gender effects. In W. R. Hayne (Ed.), Advances in child development and behavior (Vol. 23, pp. 113-149). San Diego, CA: Academic Press.

Martin, C. L. (1993). New directions for investigating children's gender knowledge. Developmental Review, 13, 184-204.

Martin, C. L. (1999). A developmental perspective on gender effects and gender concepts. In W. B. Swann, J. H. Langlois, \& L. A. Gilbert (Eds.), Sexism and stereotypes in modern society: The gender science of Janet Taylor Spence (pp. 45-73). Washington, DC: American Psychological Association.

Martin, C. L. (2000). Cognitive theories of gender development. In T. Eckes \& H. M. Trautner (Eds.), The developmental social psychology of gender (pp. 91-121). Mahwah, NJ: Erlbaum.

Martin, C. L., \& Bullock, M. (1986, August). Learning stereotypes: Biases in judging characteristics. Paper presented at the 94th Annual Convention of the American Psychological Association, Washington, DC.

Martin, C. L., \& Dinella, L. M. (2001). Children's gender cognitions, the social environment, and sex differences in cognitive domains. In A. M.-D. Lisi \& R. D. Lisi (Eds.), Biology, society, and behavior: The development of sex differences in cognition (pp. 207-239). Westport, CT: Ablex.

Martin, C. L., Eisenbud, L., \& Rose, H. (1995). Children's gender-based reasoning about toys. Child Development, 66, 1453-1471.

Martin, C. L., \& Fabes, R. A. (2001). The stability and consequences of young children's same-sex peer interactions. Developmental Psychology, 37, 431-446.

Martin, C. L., Fabes, R. A., Evans, S. M., \& Wyman, H. (1999). Social cognition on the playground: Children's beliefs about playing with girls versus boys and their relations to sex segregated play. Journal of Social and Personal Relationships, 16, 751-771.

Martin, C. L., \& Halverson, C. (1981). A schematic processing model of sex typing and stereotyping in children. Child Development, 52, 11191134.

Martin, C. L., \& Halverson, C. F. (1983). The effects of sex-typing schemas on young children's memory. Child Development, 54, 563-574.

Martin, C. L., \& Halverson, C. F. (1987). The roles of cognition in sex role acquisition. In D. B. Carter (Ed.), Current conceptions of sex roles and sex typing: Theory and research (pp. 123-137). New York: Praeger.

Martin, C. L., \& Little, J. K. (1990). The relation of gender understanding to children's sex-typed preferences and gender stereotypes. Child Development, 61, 1427-1439.

Martin, C. L., \& Parker, S. (1995). Folk theories about sex and race differences. Personality \& Social Psychology Bulletin, 21, 45-57.

Martin, C. L., \& Rose, H. (1991, April). Children's gender-based distinctiveness theories. Paper presented at the meetings of the Society for Research on Child Development, Seattle, WA.

Martin, C. L., \& Rose, H. (2001). Consistency in sex category labeling of unfamiliar stimuli using physical cues. Unpublished manuscript, Arizona State University, Tempe.
Martin, C. L., Wood, C. H., \& Little, J. K. (1990). The development of gender stereotype components. Child Development, 61, 1891-1904.

Masters, J. C., Ford, M. E., Arend, R., Grotevant, H. D., \& Clark, L. V. (1979). Modeling and labeling as integrated determinants of children's sex-typed imitative behavior. Child Development, 50, 364-371.

McDonough, L., \& Mandler, J. M. (1998). On developing a knowledge base in infancy. Developmental Psychology, 34, 1274-1288.

Medin, D. L. (1989). Concepts and conceptual structure. American Psychologist, 44, 1469-1481.

Miller, A. G. (1982). In the eye of the beholder. New York: Praeger.

Miller, C. L. (1983). Developmental changes in male/female voice classification by infants. Infant Behavior and Development, 6, 313-330.

Mischel, W. (1966). A social learning view of sex differences in behavior. In E. Maccoby (Ed.), The development of sex differences (pp. 57-81). Stanford, CA: Stanford University Press.

Money, J., \& Ehrhardt, A. A. (1972). Man and woman/boy and girl. Baltimore: John Hopkins University Press.

Montemayor, R. (1974). Children's performance in a game and their attraction to it as a function of sex-typed labels. Child Development, 45, $152-156$.

Munroe, R. H., Shimmin, H. S., \& Munroe, R. L. (1984). Gender understanding and sex role preference in four cultures. Developmental Psychology, 20, 673-682.

Nesdale, D., \& Flesser, D. (2001). Social identity and the development of children's group attitudes. Child Development, 72, 506-517.

Newman, L. S., Cooper, J., \& Ruble, D. N. (1995). Gender and computers: II. The interactive effects of gender knowledge and constancy on genderstereotypic attitudes. Sex Roles, 33, 325-351.

O'Brien, M., \& Huston, A. C. (1985). Development of sex-typed play behavior in toddlers. Developmental Psychology, 21, 866-871.

Pakizegi, B. (1984). Gender classification by infants. Journal of Genetic Psychology, 146, 135-136.

Paley, V. G. (1984). Boys and girls: Superheroes in the doll corner. Chicago: University of Chicago Press.

Perloff, R. M. (1982). Gender constancy and same-sex imitation: A developmental study. Journal of Psychology, 111, 81-86.

Perry, D. G., \& Bussey, K. (1979). The social learning theory of sex differences: Imitation is alive and well. Journal of Personality and Social Psychology, 37, 1699-1712.

Perry, D. G., White, A. J., \& Perry, L. C. (1984). Does early sex typing result from children's attempts to match their behavior to sex role stereotypes? Child Development, 55, 2114-2121.

Poulin-Dubois, D., Serbin, L. A., \& Derbyshire, A. (1998). Toddlers' intermodal and verbal knowledge about gender. Merrill-Palmer Quarterly, 44, 338-354.

Poulin-Dubois, D., Serbin, L. A., Eichstedt, J. A., Sen, M. G., \& Beissel, C. F. (2002). Men don't put on make-up: Toddlers' knowledge of the gender stereotyping of household activities. Social Development, 11, $166-181$.

Poulin-Dubois, D., Serbin, L. A., Kenyon, B., \& Derbyshire, A. (1994). Infants' intermodal knowledge about gender. Developmental Psychology, 30, 436-442.

Richner, E. S., \& Nicolopoulou, A. (2001). The narrative construction of differing conceptions of the person in the development of young children's social understanding. Early Education and Development, 12, 393-432.

Roopnarine, J. L. (1986). Mothers' and fathers' behaviors toward the toy play of their infant sons and daughters. Sex Roles, 14, 59-68.

Rothbart, M., \& Taylor, M. (1990). Category labels and social reality: Do we view social categories as natural kinds? In G. Semin \& K. Fiedler (Eds.), Language, interaction, and social cognition (pp. 11-36). London: Sage.

Ruble, D. N. (1994). A phase model of transitions: Cognitive and motiva- 
tional consequences. In M. Zanna (Ed.), Advances in experimental social psychology (Vol. 26, pp. 163-214). New York: Academic Press.

Ruble, D. N., Alvarez, J. M., Bachman, M., Cameron, J. A., Fuligni, A. J., Garcia Coll, C., \& Rhee, E. (in press). The development of a sense of "we": The emergence and implications of children's collective identity. In M. Bennett \& F. Sani (Eds.), The development of the social self. East Sussex, England: Psychology Press.

Ruble, D. N., Balaban, T., \& Cooper, J. (1981). Gender constancy and the effects of sex-typed televised toy commercials. Child Development, 52, 667-673.

Ruble, D. N., \& Goodnow, J. (1998). Social development in childhood and adulthood. In D. Gilbert \& G. Lindzey (Eds.), Handbook of social psychology (pp. 741-787). New York: McGraw-Hill.

Ruble, D. N., \& Martin, C. L. (1998). Gender development. In W. Damon (Ed.), Handbook of child psychology (5th ed., Vol. 3, pp. 933-1016). New York: Wiley.

Ruble, D. N., \& Martin, C. L. (in press). Conceptualizing, measuring, and evaluating the developmental course of gender differentiation: Compliments, queries, and quandaries. Monographs of the Society for Research in Child Development.

Ruble, D. N., \& Stangor, C. (1986). Stalking the elusive schema: Insights from development and social-psychological analyses of gender schemas. Social Cognition, 4, 227-261.

Saffran, J. R., Aslin, R. N., \& Newport, E. L. (1996, December 13). Statistical learning by 8-month-old infants. Science, 274, 1926-1928.

Saffran, J. R., Johnson, E. K., Aslin, R. N., \& Newport, E. L. (1999). Statistical learning of tone sequences by human infants and adults. Cognition, 70, 27-52.

Sears, R. R., Maccoby, E. E., \& Levin, H. (1957). Patterns of child rearing. Evanston, IL: Row, Peterson.

Sen, M., \& Bauer, P. (2001). Correlates of gender-based schematic processing in 24- and 30-month-old children. Manuscript submitted for publication.

Serbin, L. A., Poulin-Dubois, D., Colburne, K. A., Sen, M. G., \& Eichstedt, J. A. (2001). Gender stereotyping in infancy: Visual preferences for and knowledge of gender-stereotyped toys in the second year. International Journal of Behavioral Development, 25, 7-15.

Serbin, L. A., Poulin-Dubois, D., \& Eichstedt, J. A. (in press). Infants' responses to gender-inconsistent events. Infancy.

Serbin, L. A., Powlishta, K. K., \& Gulko, J. (1993). The development of sex typing in middle childhood. Monographs of the Society for Research in Child Development, 58(2, Serial No. 232).

Shell, R., \& Eisenberg, N. (1990). The role of peers' gender in children's naturally occurring interest in toys. International Journal of Behavioral Development, 13, 373-388.

Sherman, J. W., \& Klein, S. B. (1994). The development and representation of personality impressions. Journal of Personality and Social Psychology, 67, 972-983.

Signorella, M. L. (1987). Gender schemata: Individual differences and context effects. In L. S. Liben \& M. L. Signorella (Eds.), New directions for child development: Children's gender schemata (Vol. 38, pp. 2337). San Francisco: Jossey-Bass.

Signorella, M. L., Bigler, R. S., \& Liben, L. S. (1993). Developmental differences in children's gender schemata about others: A meta-analytic review. Developmental Review, 13, 147-183.

Signorella, M. L., \& Liben, L. S. (1984). Recall and reconstruction of gender-related pictures: Effects of attitudes, task difficulty, and age. Child Development, 55, 393-405.

Slaby, R. G., \& Frey, K. S. (1975). Development of gender constancy and selective attention to same-sex models. Child Development, 52, 849856.

Smith, E. R., \& Zarate, M. A. (1992). Exemplar-based model of social judgment. Psychological Review, 99, 3-21.
Smith, P. L., \& Daglish, L. (1977). Sex differences in parent and infant behavior in the home. Child Development, 48, 1250-1254.

Stangor, C., \& Lange, J. E. (1994). Mental representation of social groups: Advances in understanding stereotypes and stereotyping. Advances in Experimental Social Psychology, 26, 351-416.

Stangor, C., \& Ruble, D. N. (1987). Development of gender role knowledge and gender constancy. In L. S. Liben \& M. L. Signorella (Eds.), New directions for child development: Children's gender schemata (Vol. 38, pp. 5-22). San Francisco: Jossey-Bass.

Stangor, C., \& Ruble, D. N. (1989). Differential influences of gender schemata and gender constancy on children's information processing and behavior. Social Cognition, 7, 353-372.

Stein, A. H., Pohly, S., \& Mueller, E. (1971). The influence of masculine, feminine, and neutral tasks on children's achievement behavior: Expectancies of success and attainment value. Child Development, 42, 195207.

Stipek, D., Gralinski, H., \& Kopp, C. (1990). Self-concept development in the toddler years. Developmental Psychology, 26, 972-977.

Szkrybalo, J., \& Ruble, D. N. (1999). "God made me a girl”: Sex-category constancy judgments and explanations revisited. Developmental Psychology, 35, 393-402.

Tajfel, H. (1981). Human groups and social categories. Cambridge, England: Cambridge University Press.

Tajfel, H., \& Turner, J. C. (1986). The social identity theory of intergroup behavior. In S. Worchel \& W. G. Austin (Eds.), Psychology of intergroup relations (pp. 7-24). Chicago: Nelson-Hall.

Tajfel, H., \& Wilkes, A. L. (1963). Classification and quantitative judgment. British Journal of Social Psychology, 54, 101-114.

Tamis-LeMonda, C. S., Bornstein, M. H., Kahana-Kalman, R., Baumwell, L., \& Cyphers, L. (1998). Predicting variation in the timing of linguistic milestones in the second year: An events-history approach. Journal of Child Language, 25, 675-700.

Taylor, L., Ruble, D. N., Sumner, M., \& Szkrybalo, J. (2002). What is the nature of the relation between level of gender constancy understanding and gender rigidity? Unpublished manuscript.

Taylor, M. G. (1996). The development of children's beliefs about social and biological aspects of gender differences. Child Development, 67, $1555-1571$

Taylor, R. D., \& Carter, D. B. (1987). The association between children's gender understanding, sex-role knowledge, and sex-role preferences. Child Study Journal, 17, 185-195.

Thelen, E., \& Smith, L. B. (1998). Dynamic systems theories. In W. Damon (Ed.), Handbook of child psychology (pp. 563-635). New York: Wiley.

Thompson, S. K. (1975). Gender labels and early sex role development. Child Development, 46, 339-347.

Trautner, H. M. (1992). The development of sex-typing in children-A longitudinal analysis. German Journal of Psychology, 16, 183-199.

Turner, J. C., Hogg, M. A., Oakes, P. J., Reicher, S. D., \& Wetherell, M. S. (1987). Rediscovering the social group: A self-categorization theory. Oxford, England: Blackwell.

Udry, J. R. (2000). Biological limits of gender construction. American Sociological Review, 65, 443-457.

Walker-Andrews, A. S., Bahrick, L. E., Raglioni, S. S., \& Diaz, I. (1991). Infants' bimodal perception of gender. Ecological Psychology, 3, 55-75.

Warin, J. (2000). The attainment of self-consistency through gender in young children. Sex Roles, 42, 209-231.

Wehren, A., \& De Lisi, R. (1983). The development of gender understanding: Judgments and explanations. Child Development, 54, 1568-1578.

Weinraub, M., Clemens, L. P., Sockloff, A., Etheridge, R., Gracely, E., \& Myers, B. (1984). The development of sex role stereotypes in the third year: Relationships to gender labeling, gender identity, sex-typed toy preferences, and family characteristics. Child Development, 55, 14931503. 
Welch-Ross, M. K., \& Schmidt, E. R. (1996). Gender-schema development and children's constructive story memory: Evidence for a developmental model. Child Development, 67, 820-835.

Yee, M., \& Brown, R. (1994). The development of gender differentiation in young children. British Journal of Social Psychology, 33, 183-196.

Younger, B. A., \& Fearing, D. D. (1999). Parsing items into separate categories: Developmental change in infant categorization. Child Development, 70, 291-303.

Zelazo, P. D., Reznick, J. S., \& Pinon, D. E. (1995). Response control and the execution of verbal rules. Developmental Psychology, 31, $508-517$.
Zucker, K. J., Bradley, M. D., Kuksis, M., Pecore, K., Birkenfeld-Adams, A., Doering, R. W., et al. (1999). Gender constancy judgments in children with a gender identity disorder: Evidence for a developmental lag. Archives of Sexual Behavior, 28, 475-502.

Zucker, K. J., Wilson-Smith, D. N., Kurita, J. A., \& Stern, A. (1995). Children's appraisals of sex-typed behavior in their peers. Sex Roles, 33, 703-725.

Received November 29, 2001

Revision received June 6, 2002

Accepted June 7, 2002

\section{Call for Nominations}

The Publications and Communications $(\mathrm{P} \& \mathrm{C})$ Board has opened nominations for the editorships of Contemporary Psychology: APA Review of Books, Developmental Psychology, and Psychological Review for the years 2005-2010. Robert J. Sternberg, PhD, James L. Dannemiller, $\mathrm{PhD}$, and Walter Mischel, PhD, respectively, are the incumbent editors.

Candidates should be members of APA and should be available to start receiving manuscripts in early 2004 to prepare for issues published in 2005. Please note that the $\mathrm{P} \& \mathrm{C}$ Board encourages participation by members of underrepresented groups in the publication process and would particularly welcome such nominees. Self-nominations are also encouraged.

Search chairs have been appointed as follows:

- Contemporary Psychology: APA Review of Books: Susan H. McDaniel, PhD, and Mike Pressley, $\mathrm{PhD}$

- Developmental Psychology: Joseph J. Campos, $\mathrm{PhD}$

- Psychological Review: Mark I. Appelbaum, PhD

To nominate candidates, prepare a statement of one page or less in support of each candidate. Address all nominations to the appropriate search committee at the following address:

Karen Sellman, P\&C Board Search Liaison

Room 2004

American Psychological Association

750 First Street, NE

Washington, DC 20002-4242

The first review of nominations will begin November 15, 2002. The deadline for accepting nominations is November 25, 2002. 